University of Redlands

\title{
A Collaborative Web Application for the Lebu Migration
}

\author{
A Major Individual Project submitted in partial satisfaction of the requirements \\ for the degree of Master of Science in Geographic Information Systems \\ by \\ Marc A. Guidry \\ Fang Ren, Ph.D., Committee Chair \\ Mark Kumler, Ph.D.
}

December 2011 
A Collaborative Web Application for the Lebu Migration

Copyright @ 2011

by

Marc Guidry 
The report of Marc Guidry is approved.

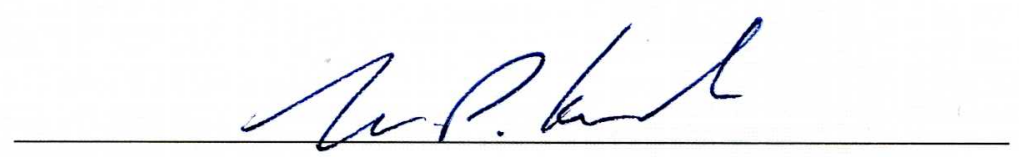

Mark Kumler, Ph.D.

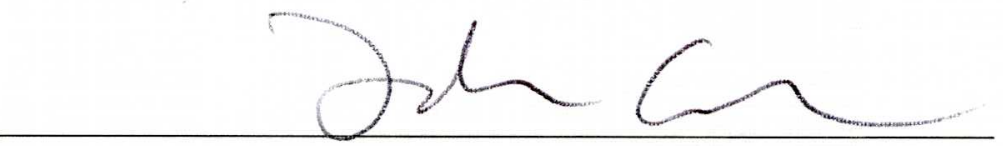

John Glover, Ph.D.

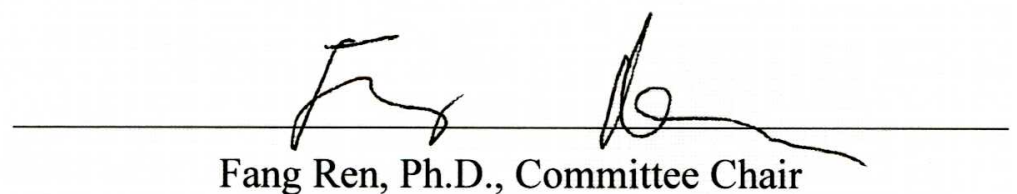

December 2011 



\section{Acknowledgements}

There are many people who have assisted me along my way to completing the MS GIS program at the University of Redlands. I would like to thank the entire MS GIS faculty and staff, but especially my committee: Dr. Mark Kumler - for your relentless yet valuable paper and poster edits; Dr. Fang Ren-my advisor, for guiding me along the entire MIP journey; thank you. Dr. John Glover, the client for my project; you were great to work with. Andre and April, I'll miss our Lakers games on the projector in 103 (good thing there wasn't a basketball season during MIP season). For my parents, whose guidance and encouragement throughout my life has been critical to my accomplishments. Finally, to Justine - your edits were expert and timely, and your love and support unending. 



\begin{abstract}
A Collaborative Web Application for the Lebu Migration

by

Marc Guidry

From the years 1000 to 1790, the families of the Lebu collective migrated from the Hodh region of present-day Mauritania, across Senegal, to the Cap-Vert Peninsula. Dr. John Glover, Professor and Chair of the Department of History at the University of Redlands, studies the history of the Lebu. In his research, Dr. Glover gathered the locations of many of the Lebu village sites, with plans to analyze the patterns of the Lebu migration. This project developed a web GIS application with which the client would be able to visualize the Lebu migration patterns and share the information worldwide. Additionally, the web application allows the users to contribute additional data about the Lebu
\end{abstract} migration, improving the database. 



\section{Table of Contents}

Chapter 1 - Introduction ......................................................................................... 1

$1.1 \quad$ Client

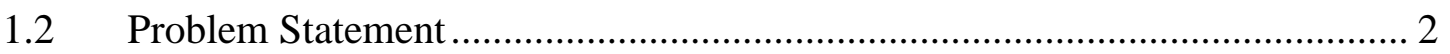

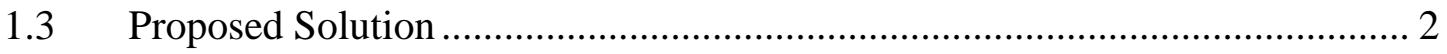

1.3.1 Goals and Objectives …………………………..................................... 2

1.3.2 Scope

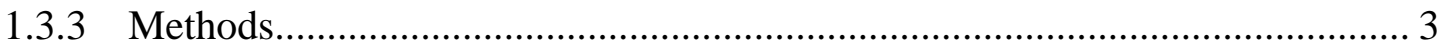

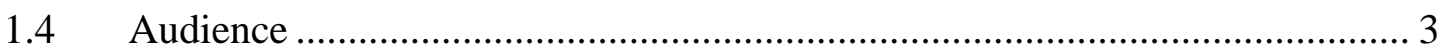

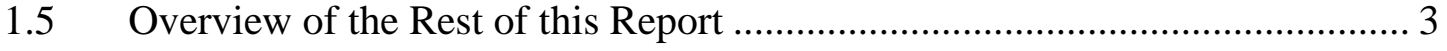

Chapter 2 - Background and Literature Review ................................................................ 5

2.1 Examining Migrations with Historical Maps................................................... 6

2.2 Lebu Migration .............................................................................. 5

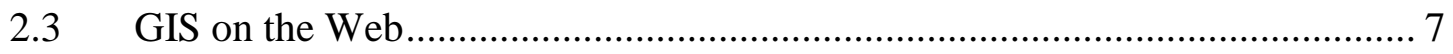

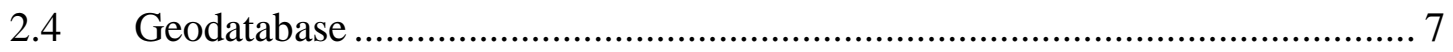

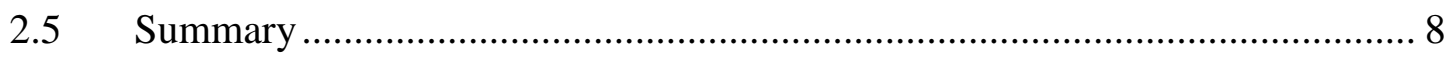

Chapter 3 - Systems Analysis and Design............................................................................ 9

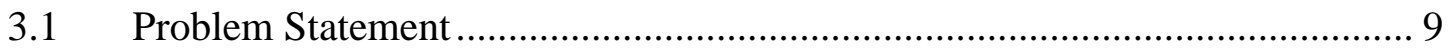

3.2 Requirements Analysis ......................................................................... 10

3.2.1 Functional Requirements ............................................................................ 11

3.2.2 Non-Functional Requirements ................................................................... 11

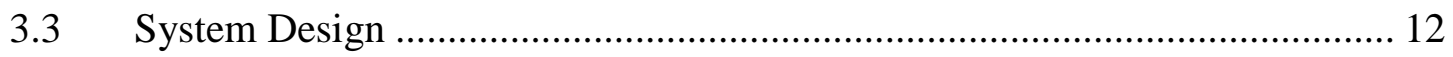

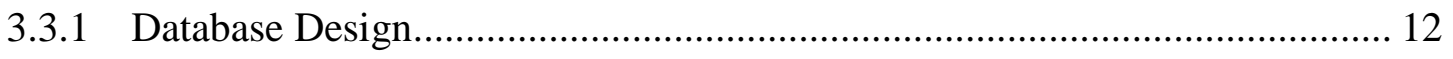


3.3.2 Map Documents Design...................................................................... 12

3.3.3 Web Application Design............................................................................ 13

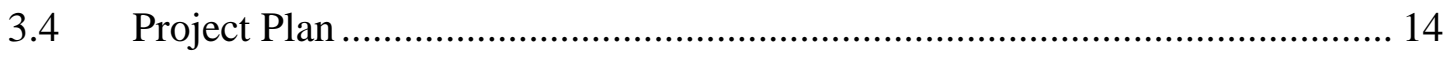

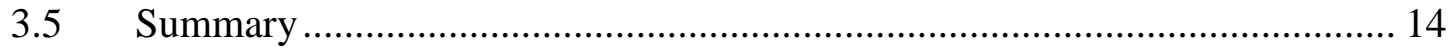

Chapter 4 - Database Design..................................................................................................... 17

4.1 Conceptual Data Model ............................................................................. 17

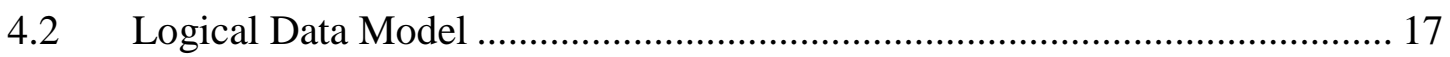

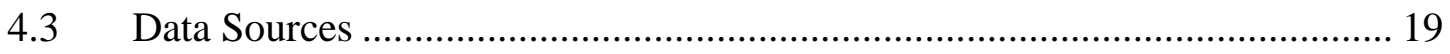

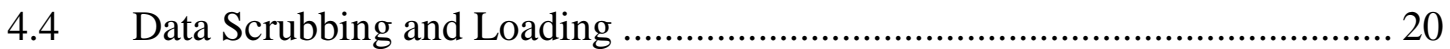

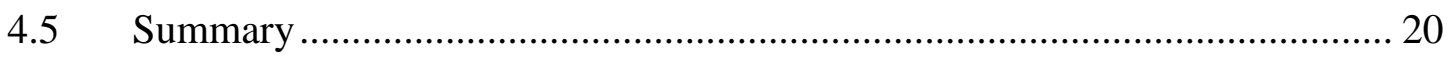

Chapter 5 - Implementation............................................................................................ 21

5.1 Web Application Development................................................................... 21

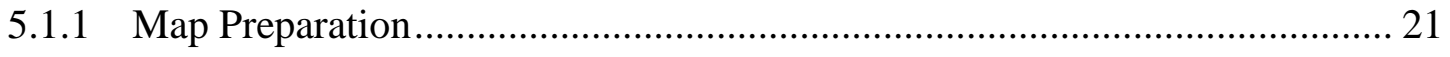

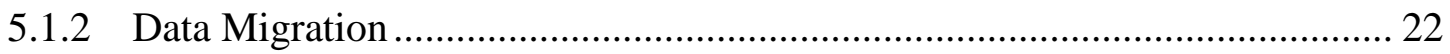

5.1.3 Publishing the Map Services.................................................................. 23

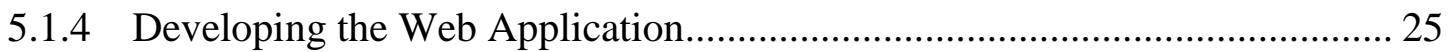

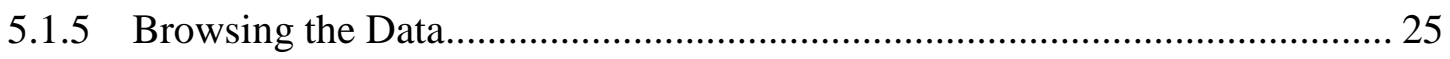

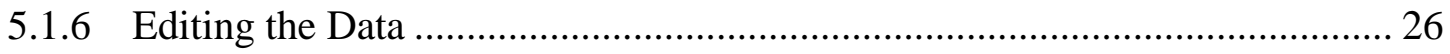

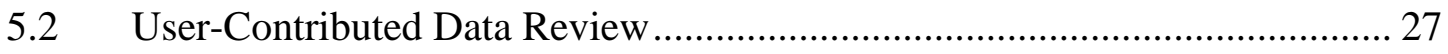

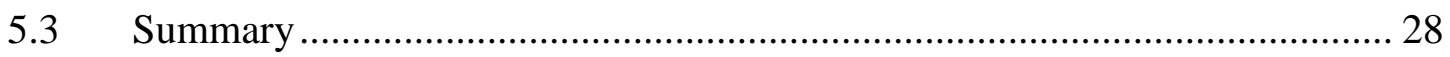

Chapter 6 - Use Cases ........................................................................................................... 29

6.1 Use Case 1: Browsing the Data ..................................................................... 29

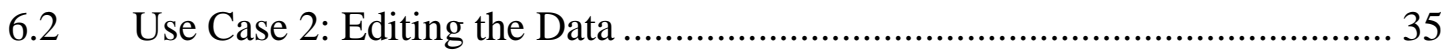


6.3 Summary

Chapter 7 - Conclusions and Future Work ...................................................................... 39

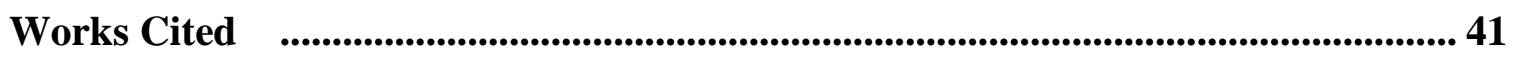

Appendix A. Web Map Application Code ........................................................................ 43

Appendix B. Data Review Directions................................................................................ 63 



\section{Table of Figures}

Figure 1-1 Lebu Migration from 1000 to 1790 ............................................. 1

Figure 2-1 Sample versioning workflow ....................................................... 8

Figure 3-1 1853 Map of Lebu Villages ...................................................... 10

Figure 3-2 Lebu Migration Web Application - standard view......................... 13

Figure 3-3 Lebu Migration Web Application - editor view ............................. 14

Figure 4-1 Conceptual Data Model ............................................................ 17

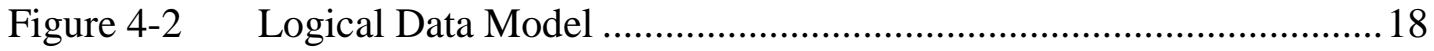

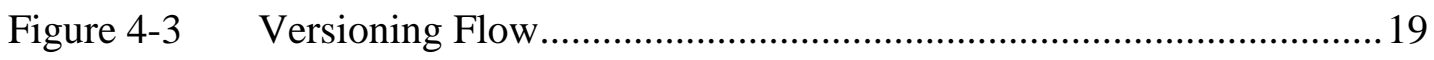

Figure 5-1 Map Documents to be Published ............................................... 22

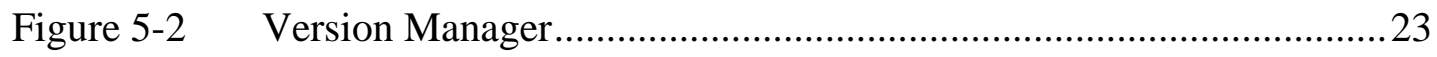

Figure 5-3 Publish Service from ArcCatalog ….......................................... 24

Figure 5-4 Map Service Publishing Toolbar .................................................24

Figure 5-5 Map Service Publishing Options .............................................. 24

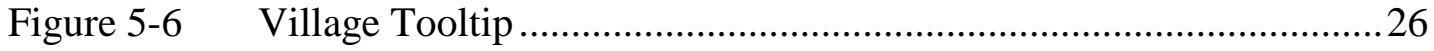

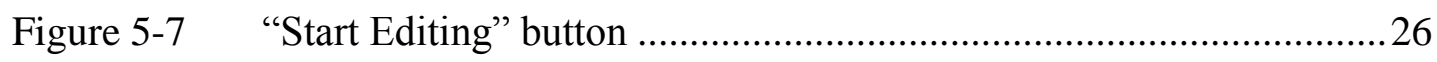

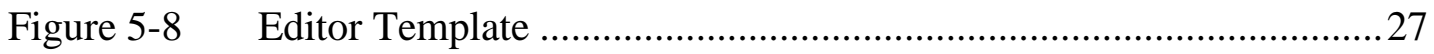

Figure 5-9 Versioning Toolbar and Version Changes Button ..........................2

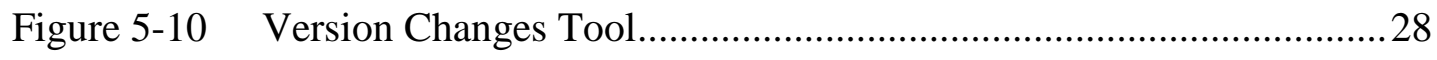

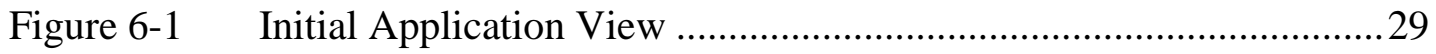

Figure 6-2 ToolTip of a Lebu Village ...................................................... 30

Figure 6-3 Lebu Family Selection ....................................................... 31

Figure 6-4 Lebu and French Developments ............................................... 32 


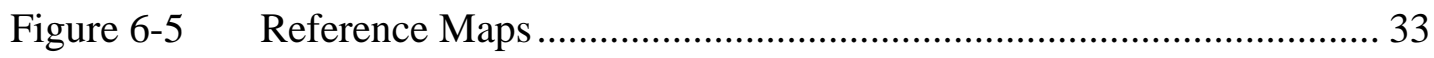

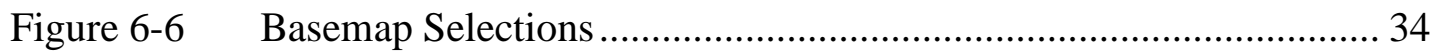

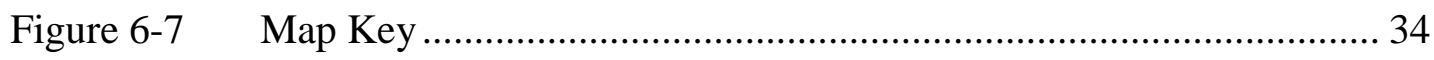

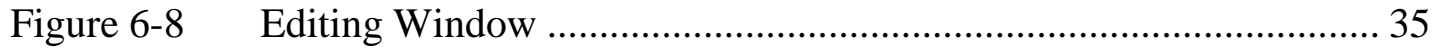

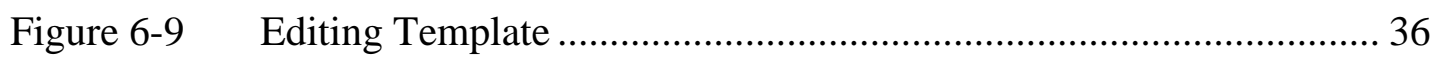

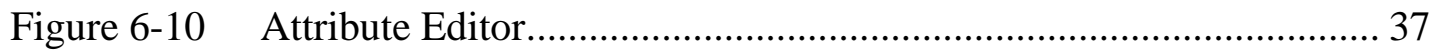

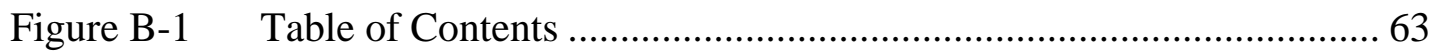

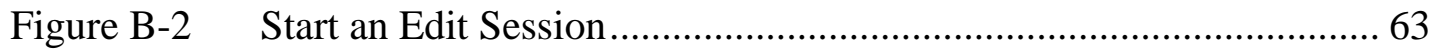

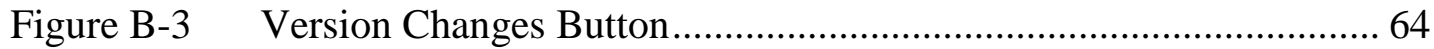

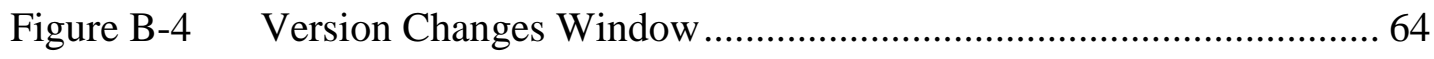

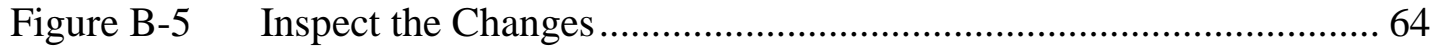

Figure B-6 Attribute Button on the Editor Toolbar ...................................... 65

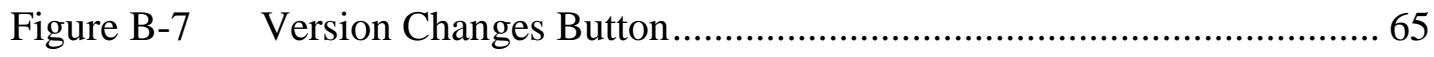

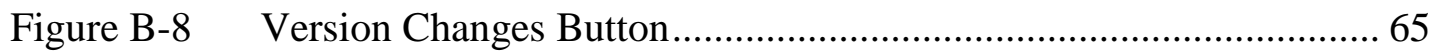




\section{List of Tables}

Table 3-1 Functional requirements..................................................................... 11

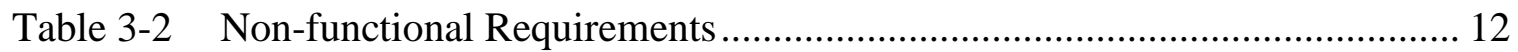





\section{List of Acronyms and Definitions}

$\begin{array}{ll}\text { GIS } & \text { Geographic Information Systems } \\ \text { HTTP } & \text { Hypertext Transfer Protocol } \\ \text { HTML } & \text { Hypertext Markup Language } \\ \text { URL } & \text { Universal Resource Locator } \\ \text { VGI } & \text { Volunteered Geographic Information } \\ \text { TIFF } & \text { Tagged Image File Format } \\ \text { WGS } & \text { World Geodetic System } \\ \text { RDBMS } & \text { Relational Database Management System } \\ \text {.mxd } & \text { ArcGIS Map Document } \\ \text { OSM } & \text { OpenStreetMap } \\ \text { USGS } & \text { United States Geological Survey } \\ \text { DEM } & \text { Digital Elevation Model } \\ \text { API } & \text { Application Programming Interface } \\ \text { SDK } & \text { Software Development Kit } \\ \text { IDE } & \text { Integrated Development Environment } \\ \text { XML } & \text { Extensible Markup Language }\end{array}$





\section{Chapter 1 - They Introduction}

From the years 1000 to 1790 , the families of the Lebu collective migrated across northwestern Africa. Starting in the Hodh region of present-day Mauritania, they traveled across Senegal, and finally ended on the Cap-Vert (green cape) Peninsula near present-day Dakar (Figure 1-1). They lived there until the late nineteenth century when the French government wanted to use the area for strategic military post. As the French began building a city near their villages, some of the Lebu voluntarily retreated northward. By 1857, the French had totally seized control of present-day Dakar (Glover, 2011).

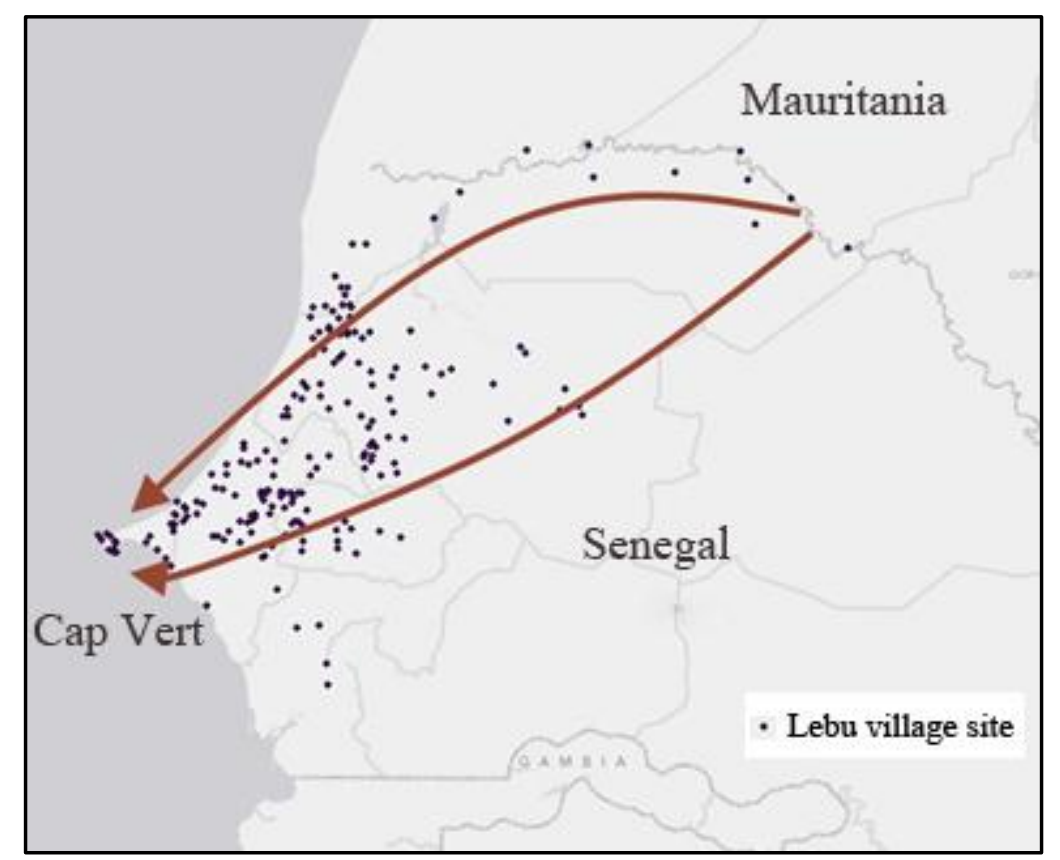

Figure 1-1 Lebu Migration from 1000 to 1790

The purpose of this project was to create a system to visualize the Lebu migration and share that information worldwide utilizing a geographic information system (GIS). Additionally, the system could take in new data about the migration through a web map interface. This would allow experts in the field to contribute their knowledge in order to improve the data on the Lebu migration.

This chapter introduces some of the major components of the project including the client in Section 1.1 and the problem statement in Section 1.2. Section 1.3 discusses the proposed solution which includes the goals, objectives, scope, and methods of this project. In Section 1.4, the audience for this report is defined, and finally, there is an overview of the rest of the report. 


\subsection{Client}

The client for this project was Dr. John Glover, Professor and Chair of the Department of History at the University of Redlands. He studies the history of the Lebu collective that has lived on the Cap-Vert Peninsula in Senegal since at least the early eighteenth century. Dr. Glover spent the summer of 2009 in Senegal conducting archival research and fieldwork. This peaked his interest in identifying spatial patterns in the Lebu migration. Upon returning, Dr. Glover set out to find a way to share his research and collaborate with other African historians via a web map.

\subsection{Problem Statement}

In his research, Dr. Glover gathered the locations of many of the Lebu village sites. These data were collected from many sources including transcribed oral sources, various books, and maps. He envisioned a solution that would provide him with an interactive visual of the spatial patterns of the Lebu's migration in the $19^{\text {th }}$ century. Additionally, Glover needed a way to share that information with colleagues worldwide. This would allow him to explore the effects that the French development of colonial Dakar had on the Lebu migration.

\subsection{Proposed Solution}

The proposed solution to address the client's needs was to develop a web GIS application with which the client would be able to visualize the Lebu migration patterns and share the information with students, scholars, and Lebu descendants. Additionally, the proposed web application would allow the users to contribute additional data. User contributions would include adding new data, modifying existing data, and removing data. Finally, a poster-size map, illustrating the migration flow of the Lebu families was proposed.

\subsubsection{Goals and Objectives}

The first goal of the project was to visualize the Lebu migration pattern using existing data. The second goal was to create a system that would allow global users to share and contribute information to the existing database. This would help the client draw conclusions about the timing of the Lebu exit from modern-day Dakar to a settlement further north on the Cap-Vert Peninsula. It is not known when each Lebu settlement was uprooted in favor of the French expansion. By combining new contributions with the existing data, the client would have the ability to study the timing of the Lebu migration out of Dakar.

The final goal was to create a process for parsing the user-contributed data. One challenge in working with user-generated data is data accuracy verification. This project aimed to develop a workflow to aid in parsing the data so that its validity could be determined. 


\subsubsection{Scope}

There were three major components in the scope of this project. The first component was to create a basemap of Senegal's Cap-Vert Peninsula. This included gathering elevation data, georeferenced French planning and US Army Map Service maps, French and Lebu landmarks, and all Lebu village sites. The next component was to create a versioned ArcSDE Geodatabase, which would store the previously mentioned data. There is one version of the database for web editing, and it is the client's responsibility to reconcile the web-editing version with the main database. The final component was to create an interactive, user-friendly website that allows sharing between the African studies community, students, and the descendants of the Lebu migrants. By simply clicking on a particular Lebu village site on the map, users would be able to learn more about the families who lived in that specific location. Users would also have the ability to add data to the map, such as additional landmarks or village sites. They would also be able to query for specific branches of the family.

\subsubsection{Methods}

Since the proposed web GIS application would allow for multi-user editing of the data, an Enterprise ArcSDE Geodatabase was created. Unlike other types of geodatabases, such as personal and file geodatabases, the ArcSDE geodatabase can be registered as versioned. In this project, a version of the main database was created for web editing. When users are editing the web version of the geodatabase, they are actually editing their own, temporary copy of that database. When editing is complete, they must post those edits to the web version. The edits will wait for review before being included in the main database. It is the client's responsibility to assess the credibility of the user contributions.

The web application was created with the ArcGIS API for Flex. The map was published using ArcGIS Server 10, and runs on a University of Redlands MS GIS server. Prior to publishing the map to the web, it was authored in ArcMap using the data collected from the client, as well as the digitized data.

\subsection{Audience}

This report is intended for an audience with at least a basic understanding of technical GIS concepts. No particular knowledge of history of the Lebu in Senegal is necessary, as it is geared towards people who would like to understand how to create a system to collect user-contributed information over the web. This includes both database management and web development concepts.

\subsection{Overview of the Rest of this Report}

The remainder of this report is divided into six chapters. Chapter 2 is a literature review that focuses on the key subjects for this project: mapping migrations, mapping on the Web, and data management for a multi-user editing environment. Chapter 3 details the project requirements, the system design, and the changes to the project plan. Chapter 4 discusses the components to the database design, and the data preparation. Chapter 5 focuses on the project implementation, discussing the methodology used to create a 
solution for the client. Chapter 6 provides a case study for the use of the system. Finally, Chapter 7 provides the conclusions from the project, and ideas for future work. 


\section{Chapter 2 - Background and Literature Review}

GIS is a valuable tool for studying historic events. Section 2.1 describes the history and migration of the Lebu. In Section 2.2, some of the challenges for using GIS to study history are explained. . Methods of implementing a GIS on the web are discussed in Section 2.3. Finally, database design for web GIS implementations is covered in Section 2.4 .

\subsection{Lebu Migration}

The origins of the Lebu are not well known. Multiple definitions have been given to the term "Lebu," including: "teller of stories or fables," "defiant warrior," "difficult people who do not easily accept vexations or dishonor; their reactions [to such] are always brutal" (Glover 2011; Balandier Mercier, and Sarr, 1952). According to Glover (personal communication 12/8/11), the Lebu are not an ethnic group, but a collectivity. Their ethnic background is not entirely certain, but it is not homogeneous. Glover (2011), when citing Jean Loup Amselle (1976), explains that "new ethnic groups [in West Africa] are formed not from a single homogenous source but from multiple sources." This is apparent in Lebu history; the Lebu have at least the ethnic makeup of the Toucouleur, Wolof, Sérère, and Sossé, as they are connected to the Lebu migration. It is likely that the Lebu did not maintain any sort of ethnic consistency until they settled on the CapVert Peninsula .

In his research, Glover found that there are many theories on the geographic origins of the Lebu. Some possibilities for their origins include: Egypt/North Africa, Southern Sahara/Hodh/North Bank of Senegal River, Futa Toro, and Jolof. The first location in the Lebu migration where the literature starts to reach a consensus is Jander; the Lebu families established several villages in this area. It was in this area that the Lebu came across the Sérère Nones, with whom they developed alliances with, and intermarried. The population in Jandar was growing, due to the arrival of refugees from Waalo, Kajoor, and Bawol. This led to the development of social organization in the form of clans and families. The remainder of the Lebu migration was structured by the Lebu families, all the way down to the Cap-Vert Peninsula. Citing Armand-Pierre Angrand (1946), Glover (2011) explains that the rising population near Lake Tamna and the need for new farmland were the reasons many Lebu families continued their migration to the south and west. Some of the families took a more southern route, settling along the Atlantic on the southern shores of the Cap-Vert Peninsula. Other families took a more northern route, settling at a site called Thiroume on Cap-Vert. This is where the Lebu families separated into two branches for the remainder of their trek to the west (Figure 1-1). The Soumbadioune branch went to the north and west areas of the peninsula, while the Bègne branch headed down the southeast coast of the peninsula. Eventually, the Lebu made their way to the southern tip of the peninsula, where they developed 11 villages that are now present-day Dakar. They lived here under the rule of the Kajoor until they fought, and won, their independence in 1790. They enjoyed 67 years of independence as the Lebu Republic until the French colonized and began developing Dakar in 1857. Finally, in 1960, Senegal gained its independence from France. 


\subsection{Examining Migrations with Historical Maps}

There has been significant previous work in using GIS to study migrations. In his analysis on migration in England and Wales, Gregory (2000) encountered issues with changing administrative boundaries. Over the course of 50 years, the boundaries of England and Wales changed considerably. The government took censuses, but because of the changing boundaries it was difficult to reach any conclusions about the migration patterns. To address this issue, he accounted for the changing boundaries by estimating the populations in the areas where borders changed. In another study of tribal migration in east Africa, a similar problem occurred. The enumeration areas had changed between data collections, so it was challenging to obtain a tribal distribution timeline (Hirst, 1970).

Another problem often seen in ancient migration studies is that crude and historical maps used in the studies are not accurate. Some ancient maps are only spatially accurate for a small geographic area, such as a city, as the map authors may have had very little knowledge about the geography outside of their city or region. For example, Talbert and Elliot (2008) examined the Peutinger Map of Rome, and their study shows how the cartographer probably had little firsthand knowledge of the landscape. Due to its purpose - to be a graphical representation of the topology of the road network - the Peutinger map was not intended to be spatially accurate. Distances and landmarks were labeled before the roads were drawn.

Besides the accuracy of historical maps, it is also very challenging to locate them on the earth. The process of locating maps in their proper locations on the earth is called georeferencing. To georeference a map, both a known spatial coordinate system in which the map was created and a consistent scale are required. However, historical maps often do not have this spatial reference information. An alternative way to georeference a historical map is to use a basemap and find matching control points on both maps. This process introduces error to the final product; it can be very difficult to find exact matches in control points on both the historic map and the basemap (Gregory, 2003).

The scanning of historic maps may introduce another type of error in studying ancient migrations. Often, historical maps are inside books, which makes them difficult to flatten completely against a scanner. This means that distortions will be present in the scanned image wherever the map was not flat against the scanner. In addition, the paper used for very old maps is often warped which introduces distortion (Gregory, 2003).

Although a historical map only depicts a static stage of migration, migration itself is a dynamic process that requires examining multiple maps representing different timeperiods. Gregory and Ell (2007), and Massey (2005), discuss the importance of incorporating time into a historical GIS application where historical maps are used as information source. GIS is a valuable tool for studying migration because of its ability to catalog information in a database, while being able to view the information spatially. Additionally, GIS offers the possibility of performing spatial analysis to identify patterns in the data. Time helps in understanding how things have changed and how the present state came to be. There is good reason to incorporate temporal changes into a GIS, however, software manufacturers have not fully implemented time into their programs (Massey, 2005). 


\subsection{GIS on the Web}

There was a historic development for the Internet in 1990 when Tim Berners-Lee invented Hypertext Transfer Protocol (HTTP), Hypertext Markup Language (HTML), and the Uniform Resource Locator (URL). He coined his inventions the "World Wide Web," and it has changed the world dramatically, including how people use GIS. Three years later, the Xerox Corporation Palo Alto Research Center built the first web map viewer. It performed simple functions such as panning, zooming, and changing projections. These functions seem rudimentary now, but they were revolutionary for their time. These new functions enabled users to use GIS through a web browser instead of needing to have specialized software locally installed (Fu \& Sun, 2011).

A common way to view geographic information over the web is in the form of a mashup. A web mashup is "a web page or web site that combines information and services from multiple sources on the web" (Murugesan, 2007). In 2007, it was estimated that 40 percent of all web mashups were mapping mashups (Vlist, Ayers, \& Bruchez, 2007). There are numerous options for web mapping mashups: a crime map with a base map showing demographics, a conservation map showing threatened areas with an imagery basemap, or a real-time traffic map over a street basemap. Today, services such as Google Maps and ArcGIS Online allow users to create mashups with their own data, or other data available on the web (Fu \& Sun, 2011).

Another example of using GIS over the web is web-based editing. This gives the user the ability to edit the geography or attributes of a feature through a web browser instead of locally installed GIS software. An example of this comes from the North China Institute of Water Conservation and Hydroelectric Power in Zhengzhou, China. The institute purchased GIS software, but could not afford enough licenses for all students to get hands-on experience using GIS. Part of their solution was to implement ArcIMS; a server mapping application that would allow a large number of students to view and query the spatial data. They also implemented the WebEdit toolkit: a solution that allowed for editing geographic data over the web. With these implementations, students could perform their data collection in the field, author that data in a web browser, and save it to a centralized database (Tang \& Selwood, 2003).

The ability to edit GIS data over the web has led to the thriving of volunteered geographic information (VGI), as coined by Goodchild (2007). This refers to private citizens, with or without formal qualifications, creating geographic information and disseminating it through the Internet. OpenStreetMap or Wikimapia are web applications that allow users to edit the geography and attributes of streets, highways, businesses, landmarks, etc (Batty, 2010). This is also often refered to as crowdsourcing. Geocollaboration, similar to VGI, is "a group of people using GIS technology to create a collaborative environment to complete the same task" (Fu and Sun 2011). With web mapping, collaborators do not have to be in the same location or working at the same time.

\subsection{Geodatabase}

An important issue related to web editing is database design. The database design affects the speed of the application and the integrity of the data. A spatial database is a place to store the data that was collected, analyzed, or displayed. When working in an ArcGIS 
environment, an Esri geodatabase is typically the native data structure for storing information about the real world (Zeiler, 2010). There are three types of geodatabases: personal, file, and SDE. Personal geodatabases are the original geodatabase, and are based on the Microsoft Access relational database software. There are several limitations to personal geodatabases. By design, a personal geodatabase does not support access to more than one user. They also have a two-gigabyte limit, which makes them unsuitable for large datasets (Zeiler, 2010). File geodatabases alleviate many of the limitations of the personal geodatabases by making the storage capacity virtually unlimited, and allowing multiple users to access the geodatabase simultaneously. Unfortunately, file geodatabases do not support multiple editors to the same table in the geodatabase simultaneously.

To address the shortcomings of the personal and file geodatabases, an ArcSDE geodatabase needs to be used (Zeiler, 2010). An ArcSDE geodatabase is used in conjunction with an additional relational database platform, such as Microsoft SQL Server Oracle. This type of geodatabase has the ability to support unlimited editors to the database, which is necessary for actions such as editing the geodatabase via a web map (Zeiler, 2010). Another advantage of using an ArcSDE geodatabase is the ability to take advantage of versioning - the process in which multiple users can simultaneously edit a copy of the database as seen in Figure 2-1. Later, that copy of the database can be posted to the main (or default) version of the database. This allows for quality control in the editing process (Zeiler, 2010).

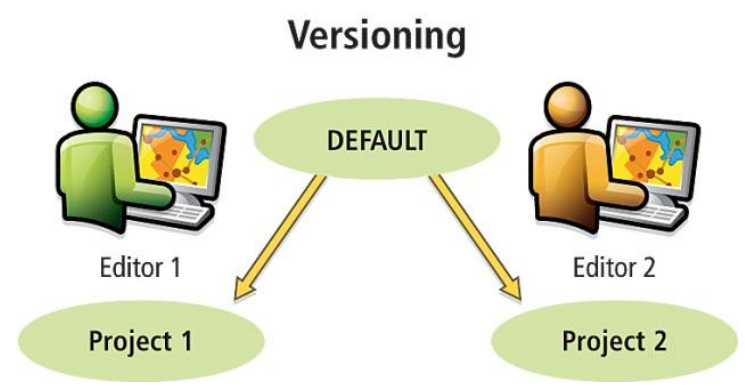

Figure 2-1 Sample versioning workflow

\subsection{Summary}

Mapping historic migrations has many inherent challenges. The data is often difficult to find, or it is found in a form that makes it challenging to perform analysis. By using database and GIS technologies, it is possible to create a system that many geographically disparate people can use to contribute their knowledge on a particular project or problem. The data collected from anonymous sources is not always correct, and there needs to be a method of quality control in place to separate the erroneous edits from the valuable, usercontributed information. To address this issue, a versioned ArcSDE geodatabase was developed, and there is a workflow for data review before the contributions are committed to the database. 


\section{Chapter 3 - Systems Analysis and Design}

The solution to any problem requires fully understanding the problem, developing a strategy, executing the strategy, and evaluating the final product. This chapter elaborates on the process for developing the solution proposed in Section 1.3. In Section 3.1 the problem is stated. Section 3.2 discusses the requirements of the proposed system. Section 3.3 addresses the system design, focusing on how the components of the project fit together. Section 3.4 introduces the plan developed to complete this project, and how it was changed during development.

\subsection{Problem Statement}

There were two major issues to be addressed. Professor Glover wanted to study the migration of the Lebu ethnic group in Senegal, and had a collection of maps and some written text discussing the locations of the Lebu village sites, but he had no way to combine those sources into a complete picture of the Lebu migration. Figure 3-1 shows a map that the client had, in his collection, which shows the locations of some of the Lebu villages. Furthermore, he had no effective means to share this data with interested parties worldwide, or to receive new and updated data from experts in the history field. 


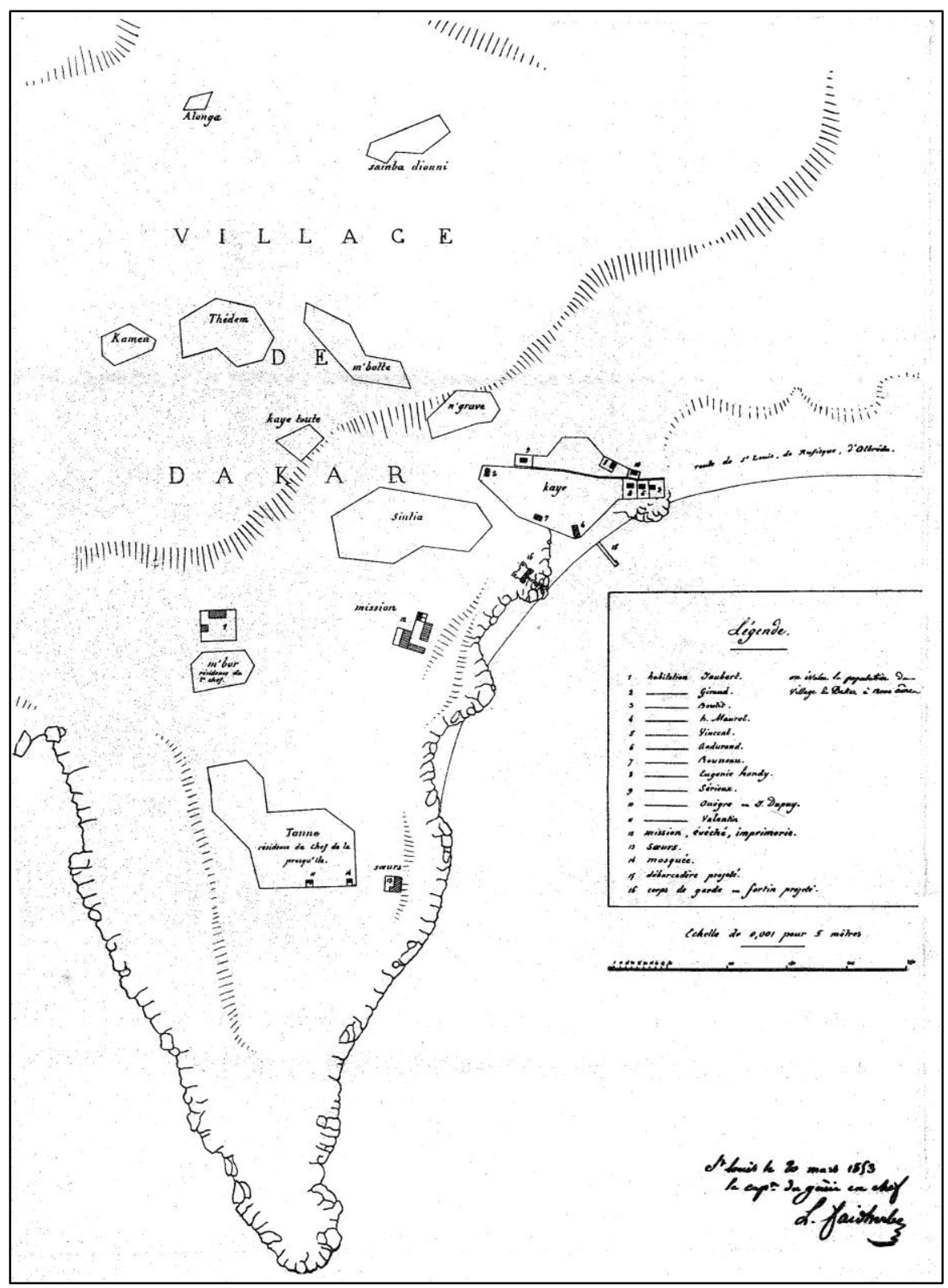

Figure 3-1: 1853 Map of Lebu Villages

\subsection{Requirements Analysis}

A critical component to a development plan is an analysis of the requirements. The deliverables for this project include a complete geodatabase, a web application, and a map poster. The following sections present analysis of the functional and non-functional requirements. 


\subsubsection{Functional Requirements}

The functional requirements are outlined in Table 3-1. The client needed to share this application with people worldwide, and many of them do not know how to use, or do not have access to, ArcGIS software. Therefore, one of the primary requirements was that the Lebu map application must work in a modern web browser, and must be simple to use. Another requirement of the application was that the user must be able to explore the data on the map. This includes the ability to pan, zoom, and click on features to learn more about the contents of the map. It was also anticipated that some of the users of this application would be history experts, and might be able to improve the existing data. Therefore, the data in the map should be user-editable. Consequently, a process for reviewing the user-contributed data would be required to ensure the quality of usercontributed data. To achieve that, users would only edit be able to edit a copy of the main database through the web application, and the copy of the main database will be periodically reviewed for accuracy by the client. After the client determines which edits are valid, those will be transferred to the main database. The final requirement was a large-format map that includes a selection of the data collected in this project.

\section{Table 3-1 Functional requirements}

\begin{tabular}{|l|}
\hline Functional Requirements \\
\hline Application works in web browser \\
\hline Explore data \\
\hline User editable \\
\hline Process for reviewing user-contributed edits \\
\hline Map poster $25 \times 25$ inches \\
\hline
\end{tabular}

\subsubsection{Non-Functional Requirements}

Table 3-2 summarizes the non-functional requirements for the Lebu web application. One requirement was that the user interface should be intuitive. The web application was designed so that the user will know what to do with minimal instructions. Another requirement was that ArcGIS Desktop 10.0 and ArcGIS Server 10.0, available at the client's university, was used for map authoring and publishing. In addition, the ArcGIS API for Flex version 2.4 was used for the development of the web application. This was the most up-to-date version of the API at the time of development. Finally, documentation for using the system was a requirement for the client. Upon completion of the project, updating the data within the application becomes the client's 
responsibility. Because that will be conducted periodically, a user's manual will be provided to ensure that this is done properly.

\section{Table 3-2 Non-functional Requirements}

\section{Non-Functional Requirements}

Intuitive user interface

Use ArcGIS Desktop and Server version 10.0 for map authoring and publishing

Use ArcGIS API for Flex v2.4 for web application

An ArcGIS Map Document for reviewing user-contributed edits

Documentation

\subsection{System Design}

The Lebu map application was designed based on the requirements analysis. There are three main components that this section will discuss: the database, map documents, and web application.

\subsubsection{Database Design}

The project data were stored in an Esri ArcSDE enterprise geodatabase. This type of geodatabase is the most robust available. It has the advantages of not having a storage limit, supporting an unlimited number of connections, and supporting versioning (Zeiler, 2010). Versioning is an important part of the web-editing functionality of the proposed application. There are two versions of the geodatabase: the default version (which is the main database), and the web-editing version (which is a copy of the main database used for edits). This will be discussed in greater detail in Chapter 5.

\subsubsection{Map Documents Design}

Two ArcMap map documents (.mxd) were created for delivery to the client. One of these was created for authoring the large-format map that displays the Lebu sites, migration flow, and elevation. The second map document was created for reviewing the usercontributed content generated from the web application. This map document shows both the main database and the web version database, which allows the client to examine what was contributed and decide which edits should be incorporated into the main database and which should be removed. 


\subsubsection{Web Application Design}

The design of the web application interface is shown in Figure 3-2. It was designed to be an intuitive, user-friendly interface that allows users to explore and edit the data on Lebu village sites and Lebu or French landmarks. The typical functions that a user would expect in a web map, such as pan and zoom, are available. When the users hover over a Lebu village site, the family name of that site will display. If they click on the site, they will be shown additional attributes, such as additional information on the family, the time that site was inhabited (if available), and the original data source for the specific site. The user can also do the same for Lebu and French landmarks. The user also has the ability to filter the Lebu villages by specific families. The default view displays all sites, but if users are interested in a specific family, they can apply a filter to include any combination of families desired. For the background basemap, the user can choose between a hillshade or OpenStreetMap. The hillshade gives users a sense of the topography of the region, and OpenStreetMap shows present-day roads, cities, and landmarks.

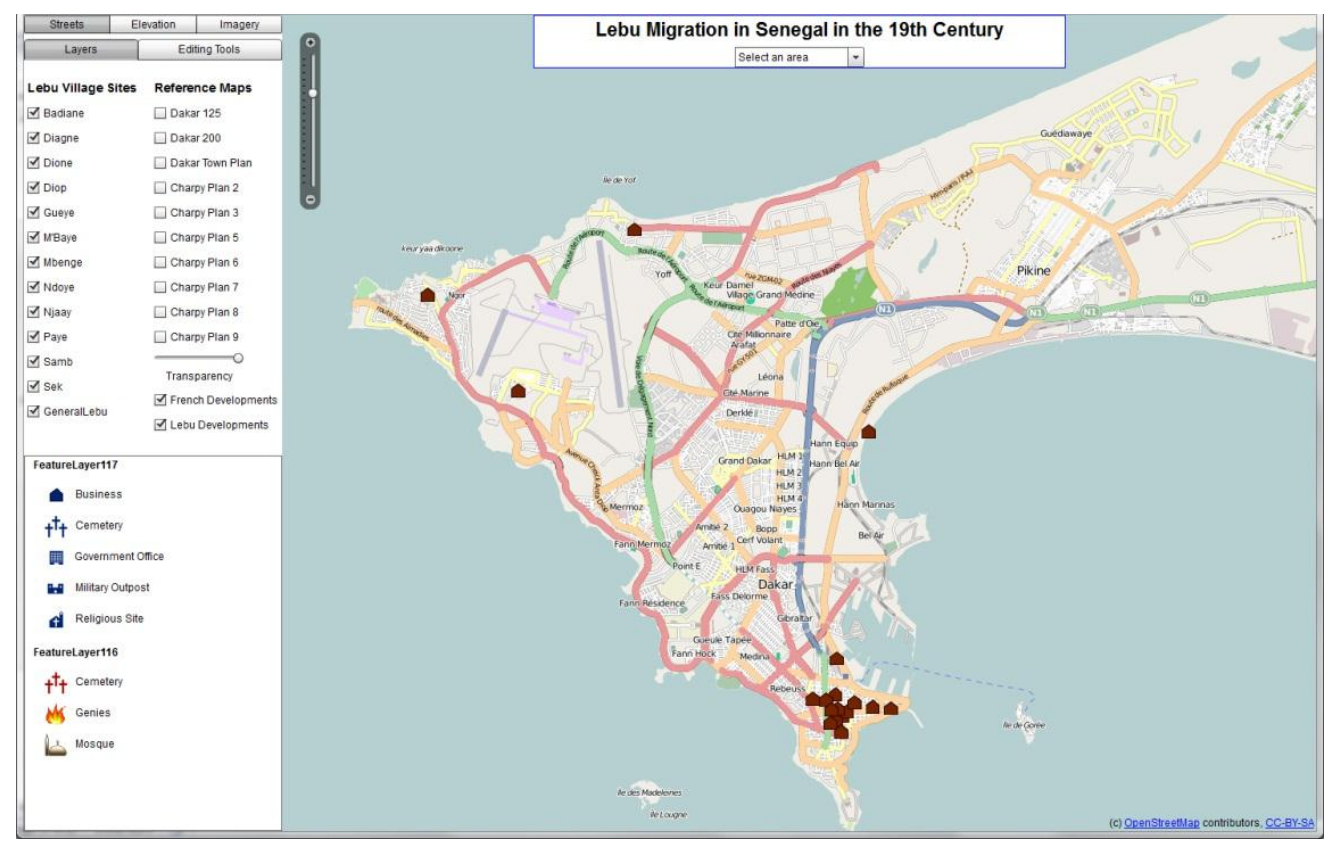

Figure 3-2 Lebu Migration Web Application - standard view

Users can also enter an editing mode to edit the data (Figure 3-3). Users can create new features or edit existing features. When they enter the editing mode, a template of features that are available for editing appears. The user then can select from the template to add new features. As soon as a feature is created or modified, it is automatically saved. 


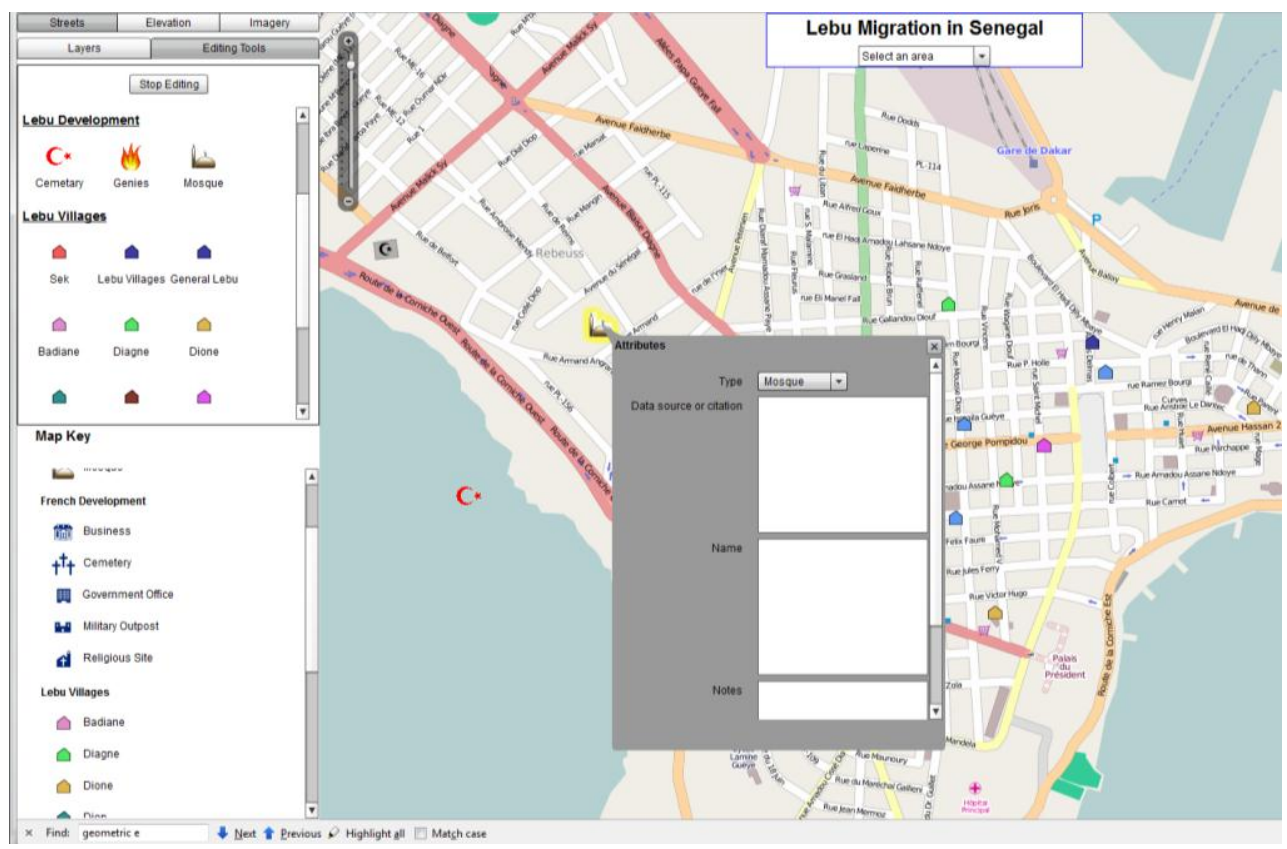

Figure 3-3 Lebu Migration Web Application - editor view

\subsection{Project Plan}

The initial project plan consisted of seven phases: a requirements analysis, data collection, system design, migration tool development, web map development, review, and product delivery. Based on the requirements analysis, the proposed solution was to analyze the migration of the Lebu, and develop a tool that estimated their migration route between known Lebu village sites. To accomplish this, variables such as climate, terrain, and political states would be used. However, during the data collection phase, it became apparent that the data required to create the migration tool was not available. The available climate data was extremely coarse and unsuitable for spatial analysis, and there was very little temporal information on the Lebu village sites throughout the migration. As a result, the proposed solution shifted from a migration tool to a web application that could collect user-contributed information to refine the data that had already been collected.

This resulted in changes to the database development. Making the data available to edit in a web application meant that the data needed to be in a versioned ArcSDE geodatabase, as opposed to a file geodatabase. Using an ArcSDE geodatabase requires using an additional RDBMS such as Microsoft SQL Server 2008, which was used in this project. The versioning of the geodatabase provides a method for the client to review the data before it is included in the main database. In addition, the initial plan had the web map being developed in the ArcGIS Flex viewer, but this was changed to a custom application developed using the ArcGIS API for Flex.

\subsection{Summary}

The initial project plan was designed based on the requirements analysis. During the data collection and system design phases, it was determined that critical data was unavailable. 
The project plan was revised to help solve a new problem. This chapter discussed the many considerations that influenced the current system design. The next chapter will discuss the data collection, data scrubbing, and database design. 



\section{Chapter 4 - Database Design}

A well-designed database is critical for this project because the required web editing function largely depends on database versioning technique. This chapter discusses the considerations that shaped the design of the database, and how it was implemented. Section 4.1 discusses the conceptual data model, which describes the components to the client's problem and how they relate to each other. Section 4.2 discusses how the conceptual model becomes a reality in a database. Section 4.3 addresses the data sources, and Section 4.4 discusses the processing of the original data before it was ready to be loaded into the database.

\subsection{Conceptual Data Model}

The conceptual data model is a diagram of the client's problem shown by the key components and their relationships with each other (Figure 4-1). This is not intended to be a representation of the database; it is only a visual description of the components of the client's problem. In this case, there was one ethnic group of concern: the Lebu. Roughly a dozen families were a part of the Lebu ethnic group, and these families lived in Lebu village sites. As the migration progressed, new village sites were established, branching off from the previous villages. Additionally, the Lebu built developments such as mosques and cemeteries.

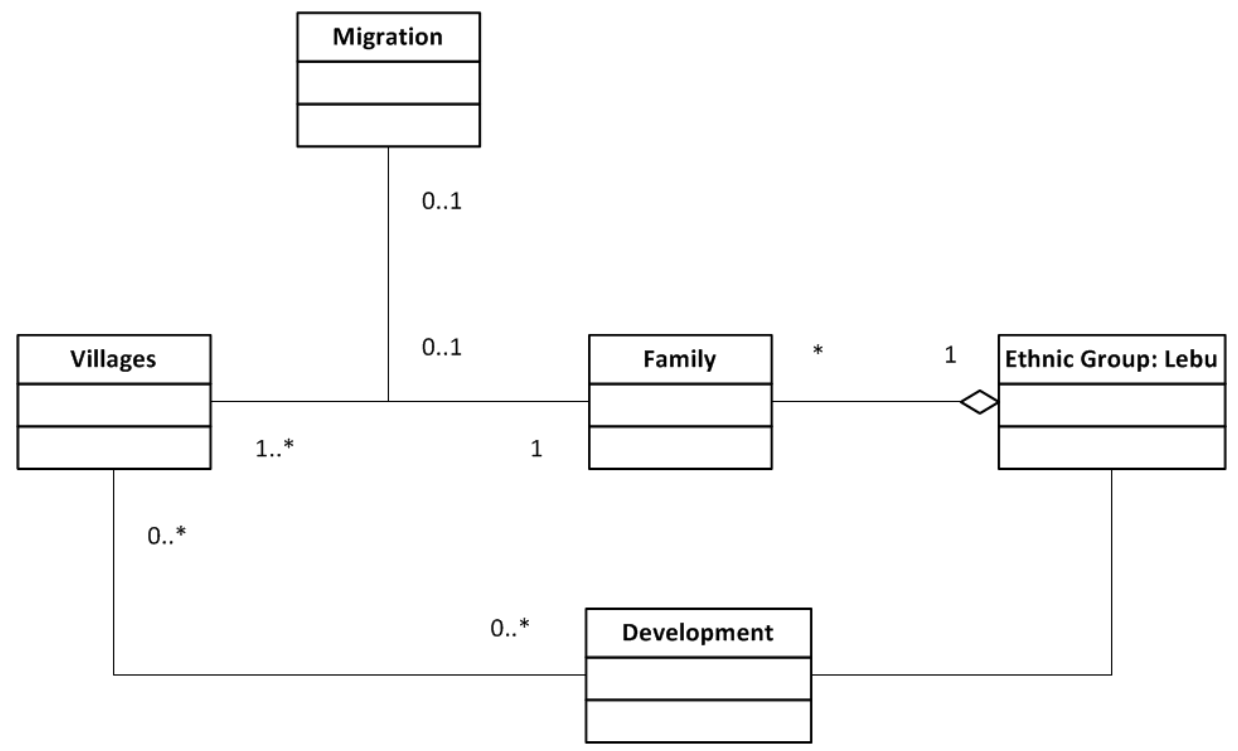

Figure 4-1 Conceptual Data Model

\subsection{Logical Data Model}

The logical data model takes the components from the conceptual data model, and organizes them in a way that can be implemented in a database (Figure 4-2). In this case, several reference maps were the source for the data about the villages, the Lebu 
developments, and the French developments. Additionally, there were Lebu families living in the villages, and multiple villages can be associated with a single family. This is due to the migration of the families who traveled from Mauritania down to the Cap-Vert Peninsula. Also, single villages can host multiple families over time; in the database, these village sites are referred to as "general Lebu."

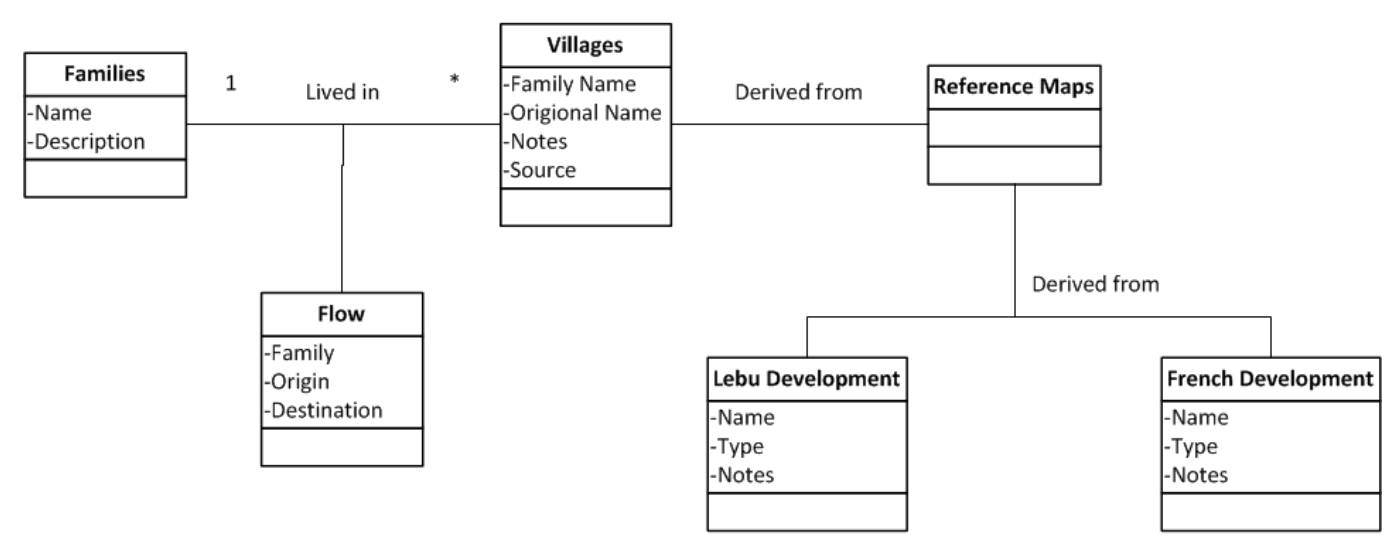

Figure 4-2 Logical Data Model

Before the files to store the features described in the logical data model can be created, the database to store these files needs to be designed. The database software was chosen based on the requirement of multi-user editing, and the availability of the software at the client's university. An Esri ArcSDE geodatabase, used in conjunction with Microsoft SQL Server, was chosen for this project. A feature of the ArcSDE geodatabase is that it supports versioning. Versioning supports very long edit sessions that can last months at a time. There can be many versions of the database, but there is always one root version called DEFAULT. This is the main database from which all child versions are created. Although there can be many child versions, only one child version would be necessary for this project, which is called the Web Editing version (Figure 4-3). In this version, edits from the web application will be made, and subsequently quality controlled. Once the contributions are vetted for accuracy, they will be posted to the default database. 


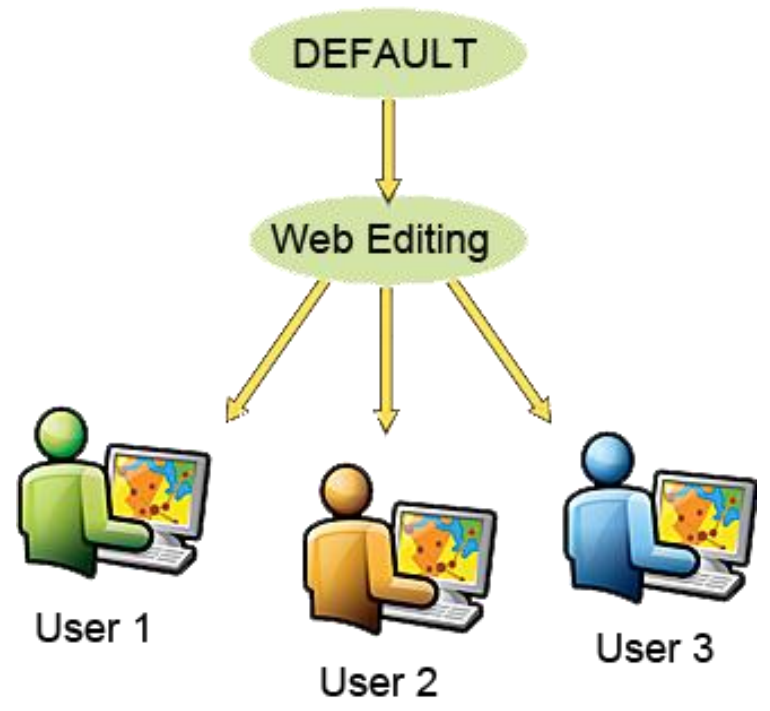

Figure 4-3 Versioning Flow

Inside the geodatabase are four point feature classes: Lebu village sites, Lebu developments, French developments, and the Lebu flow diagram. The attributes of the Lebu village sites are: family name, original name, source, notes on the village, editor, and editor qualifications. The family name is a subtype field in the feature class. In a geodatabase, subtypes provide a method for dividing a feature class into logical groups. The family name is used for grouping the data because there are twelve Lebu families, and each village is a derivative of that family. The Lebu development and the French development feature classes share the same schema, which is: the type of development (eg. church, cemetery, military outpost), the name of the development, source, notes, editor, and editor qualifications. The reason for including the editor fields in these three features classes and having two feature classes with the same schema will be discussed in Chapter 5. The final feature class stores the Lebu migration flow. The client created the flow as a general estimation of the migration routes by drawing line segments between the Lebu village sites, in the direction and order that they likely traveled in the migration. In this feature class, the only attribute is the family name.

In addition to the feature classes, the main geodatabase also contains ten raster files that are scanned and georeferenced historic maps. Seven of them are French colonial planning maps, and three of them are US Army Map Service maps.

\subsection{Data Sources}

The client provided the majority of the data used in this project. He had eight nineteenthcentury French colonial planning maps and two US Army Map Service maps that were scanned to tagged image file format (.tiff) images. They were georeferenced into the spatial reference Sierra Leone 1986 UTM Zone 28 North by the client. The client also supplied twenty-two Esri shapefiles of the Lebu village sites. The village sites were broken down by families, and there are twelve families associated with the village sites. Each family had one shapefile for the villages that were digitized based on the reference maps, and one shapefile based on any villages known through oral sources. The Lebu 
and French developments were also digitized from the reference maps. Finally, elevation data was collected in the form of a Digital Elevation Model (DEM) from the United States Geological Survey (USGS), and contours were digitized from some of the reference maps.

\subsection{Data Scrubbing and Loading}

As with almost all GIS projects, data scrubbing was performed before data were loaded into the database. In an Esri geodatabase, a feature class was created with the schema matching that of the Lebu village shapefiles, and an additional field for the family name. The twenty-four Lebu village shapefiles were then imported to the new feature class.

The reference maps also needed work before being used in the web application. Although they were previously georeferenced by the client and lined up correctly in ArcMap, they did not line up correctly in the web application. After researching what might have been going wrong, it was determined that the best solution was to obtain the original map images and re-georeference them. These were then georeferenced using the WGS 84 Web Mercator Auxiliary Sphere spatial reference; this is the spatial reference that is used in the web application.

\subsection{Summary}

This chapter discussed the considerations that went into the design and implementation of the database for this project. It started with the conceptual data model where the entities of the client's problem were diagrammed. Next was the logical data model where the conceptual model design was converted to a model that can be implemented in a database. The sources of the data used in this project were discussed, and section 4.4 described the data processing that was required before being imported to the database. 


\section{Chapter 5 - Implementation}

A custom web application for viewing and editing data related to the Lebu migration was created for this project. A workflow for reviewing user-contributed data and posting the valuable edits accompanies the web application. Additionally, the client was provided with several physical maps that he can use in the classroom or at conferences. This chapter describes the processes involved to complete the project. Section 5.1 discusses all the components required for creating the web application, which includes preparing the maps, migrating the data to the ArcSDE geodatabase, publishing the map services, and developing the web application interface and its various functions. Section 5.2 details the process of reviewing the user-contributed data.

\subsection{Web Application Development}

Creating the Lebu Migration web application was the major task of this project. This section discusses all of the development steps involved in creating this web application.

\subsubsection{Map Preparation}

After completing the data scrubbing, the next major task was to author the maps that would be published to the web; this was done in ArcGIS Desktop 10. Two key map documents (Figure 5-1) were created for publishing to ArcGIS Server 10. These two map documents include the same features: Lebu villages, Lebu developments, and French developments. The reason for having both map documents implemented is to keep the web editing and default layers on separate map services. Thus, one map document was published for web editing purposes, and the other was used to link to the default geodatabase. The villages were symbolized based on the family, and the development layers were symbolized based on the development type (e.g., cemetery, mission, mosque). Once the symbology was applied and scale ranges were set, the maps were ready to be published to the server. 


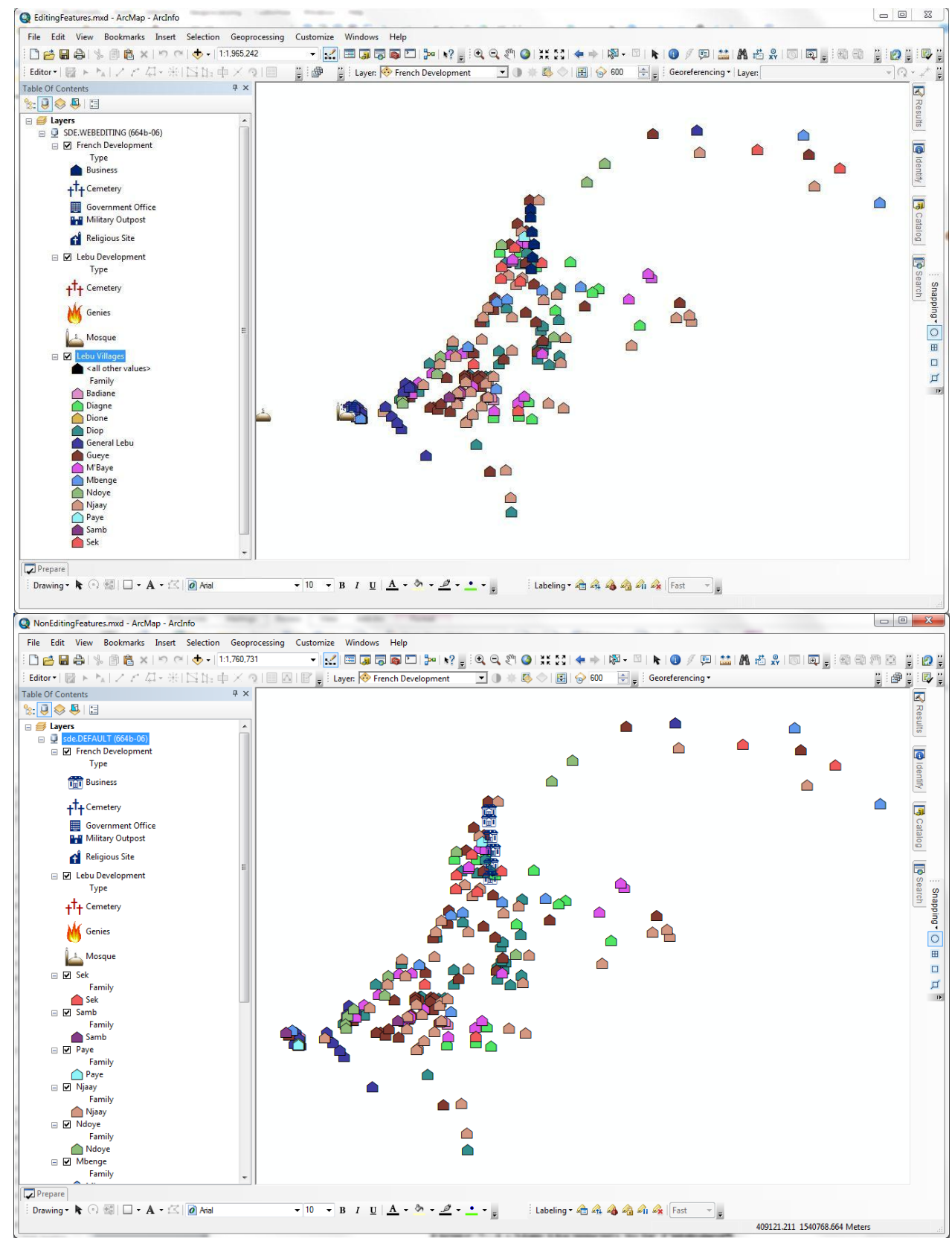

Figure 5-1 Map Documents to be Published

\subsubsection{Data Migration}

While authoring the maps, the data were stored locally in an Esri file geodatabase on the development machine. To achieve the required functionality of the web application, the data were moved to an ArcSDE geodatabase. Microsoft SQL Server and ArcSDE were installed and configured on the development machine. Using the Import Feature Class and Import Raster tools in ArcCatalog, all data were imported from the file geodatabase to the ArcSDE geodatabase. After the data migration was complete, the three feature classes (Lebu Villages, Lebu Developments, and French Developments) were registered as versioned. Then, through the Version Manager, a new web editing version of the 
database (named WEBEDITING) was created, to be used in the web application for users to edit the data (Figure 5-2). The edits are stored in the WEBEDITING database until they are reviewed for quality. In the quality-control process, these edits are either included in the main database or deleted.

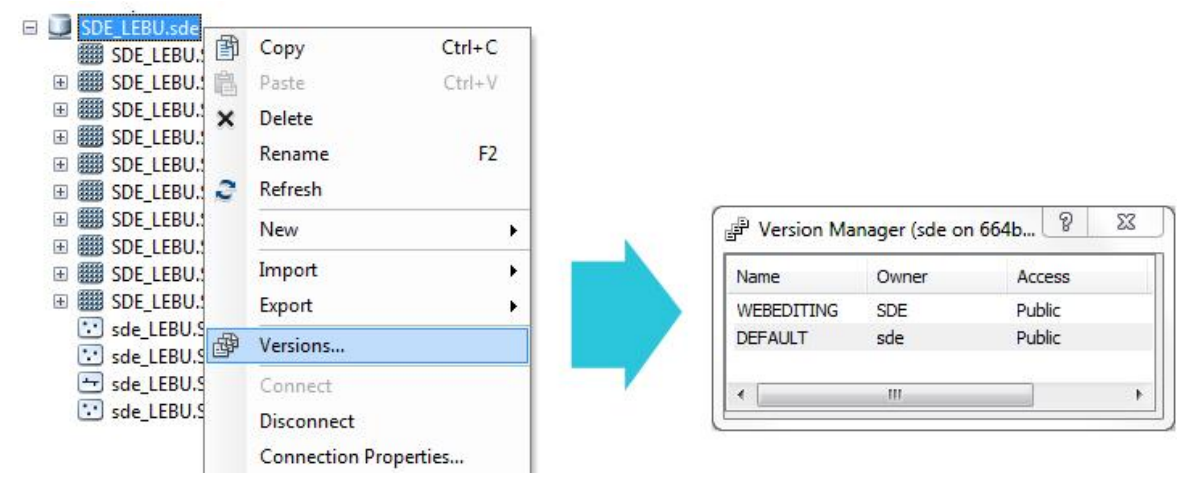

Figure 5-2 Version Manager

Once the new ArcSDE geodatabase with versions was created, the paths to the data sources of the layers in the map documents were changed to the new geodatabase location. The layers in the map document for web editing were connected to the feature classes in the WEBEDITING version of the geodatabase, and the layers of the noneditable map were connected to the DEFAULT version of the geodatabase.

\subsubsection{Publishing the Map Services}

Once the data were migrated and the maps were authored, they were needed to be published to ArcGIS Server. This was accomplished through publishing tools in both ArcGIS Desktop and ArcCatalog. The reference maps in raster format were published first because they did not need to be in a map document. To be included in the web application, the reference maps needed to be published as separate services, which was most efficiently done directly from ArcCatalog (Figure 5-3). 

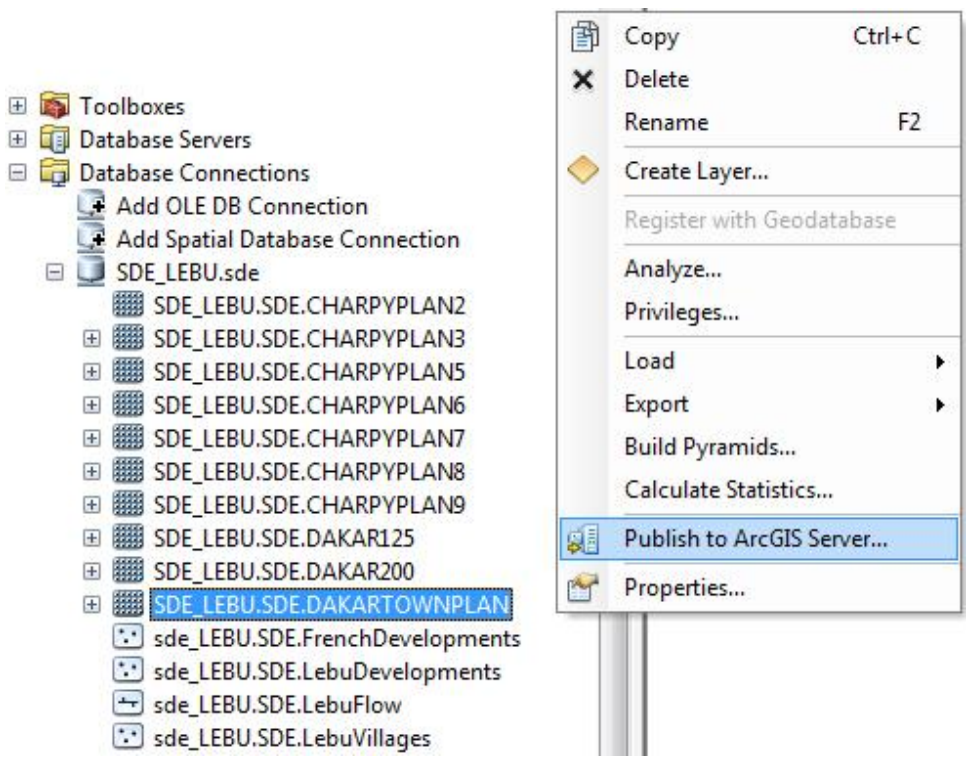

Figure 5-3 Publish Service from ArcCatalog

The map documents that were previously authored were then published using the Map Service Publishing toolbar (Figure 5-4).

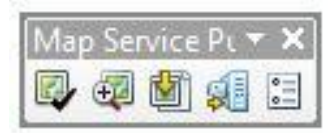

Figure 5-4 Map Service Publishing Toolbar

Three key steps for publishing a map service from a map document were followed for this project. First, it was important to run the Analyze Map tool that checks for potential errors in the map, such as unsupported symbology or inconsistent spatial references. The next step was to preview the service to ensure it performs efficiently. Finally, the publish wizard was used to run through several different options, such as service name, server, server folder, and types of capabilities for the service (Figure 5-5).
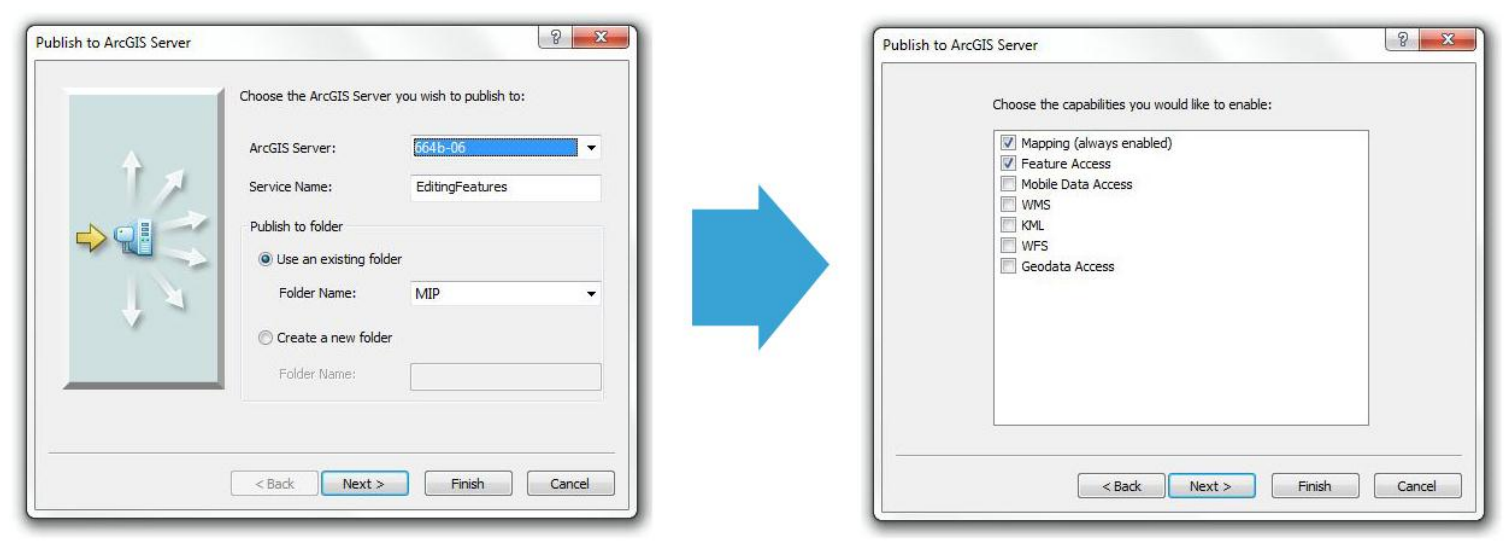

Figure 5-5 Map Service Publishing Options 
The map services required both Mapping and Feature Access capabilities. The Mapping capability is always available by default, but it does not provide access to the geometry of the features which is necessary for editing and ToolTips. Enabling the Feature Access capability is required for that functionality. Once all the data was published to the server, it was ready to develop the web application.

\subsubsection{Developing the Web Application}

This web application was developed using the ArcGIS API for Flex, one of the three web mapping APIs Esri offers. Flex is a software development kit (SDK) used for rich internet applications, such as web maps. The Adobe FlashBuilder program is an integrated development environment (IDE) designed for developing Flex applications, and it was used to develop this web application. The first step for developing the application was to create a new Flex project in FlashBuilder and import the ArcGIS library to the project. Two categories of functions were developed in the Flex project: browsing the Lebu data, and editing the data in the web; these are described in detail in the following section.

\subsubsection{Browsing the Data}

When a user first visits the web site, the application is launched in the browsing mode. The initial map extent shows the entire Cap-Vert Peninsula, including the Lebu villages, Lebu Developments, and French Developments. Each of the Lebu families is represented in a layer. This means that if users are interested in a particular set of families, they can view just those families by turning the individual family layers on and off. There are three basemaps available for users: a street map, elevation hillshade, and aerial imagery. Additionally, there are ten historical reference maps that the user can activate; a transparency can be applied to those so that the historical map can be compared to the current map. Map navigation operates very similarly to most web map applications where the user can pan and zoom in or out. An additional navigation feature is a dropdown list of bookmarks from which the user can quickly zoom to the pre-selected areas. The bookmarks are stored in an XML document on the web server, so the client can easily add new bookmarks in the future.

On the map, when the user hovers over a village site with the cursor, the original name of the village, a note about the village, and the data source displays in a ToolTip (Figure 5-6). The same functionality is available with the Lebu and French development layers. There are ToolTips displaying the name of the feature, notes, and data source attributes. 


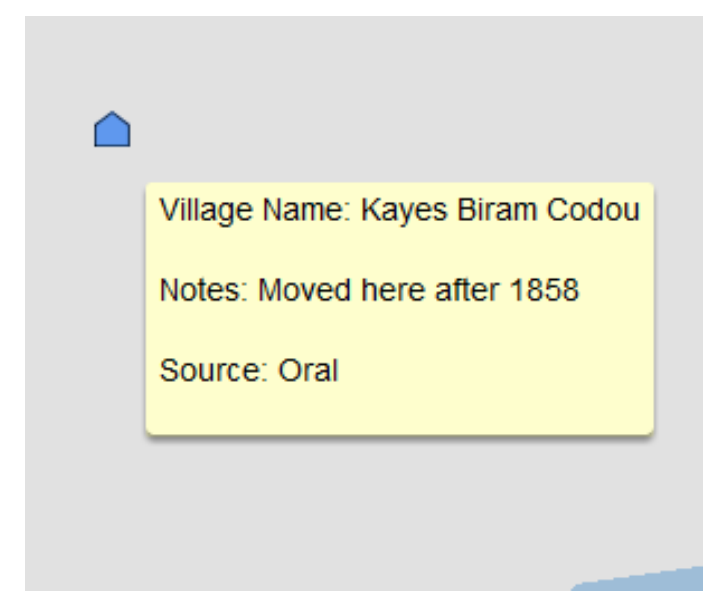

Figure 5-6 Village Tooltip

\subsubsection{Editing the Data}

The other major feature of this web application is that the user is allowed to edit the data displayed on the web. The edits can be in the form of adding a Lebu village site, French development or Lebu development, or modifying the attributes of any existing feature.

In this web application, editing is activated and deactivated through the use of states. States is a capability of Flex that presents the user with different views on the same page. There are two states in this application: "editing" and "notEditing." The majority of the user interface is the same for both states, but certain things are activated in the editing state. On the editing tab in the side bar, there is a button labeled "Start Editing" (Figure 5-7). This button is used to change the state of the application and activate the editing features.

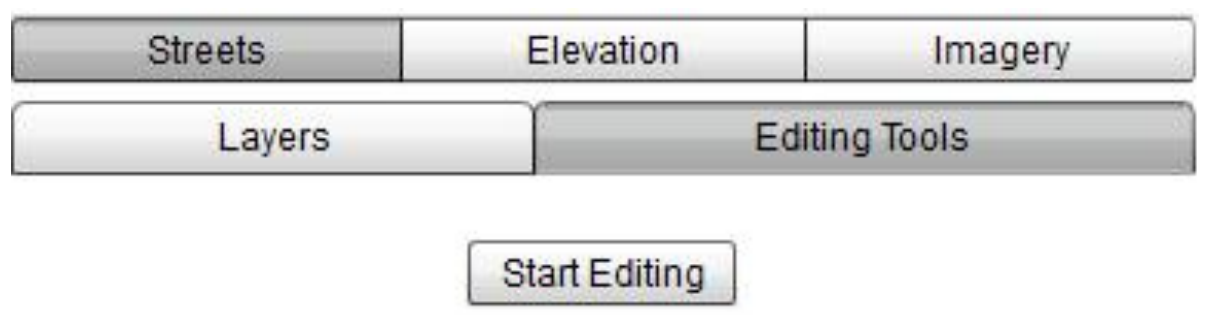

Figure 5-7 "Start Editing" button

Once the user clicks the Start Editing button, the application enters the editing state and the Editor component becomes active in the Editing Tools tab (Figure 5-8). The Editor component is part of the ArcGIS Flex API that controls editing in the Flex application. Part of the Editor component is the editing template. The editing template is a panel that shows a graphical list of the features that can be inserted into the map. There are two types of edits that can be made in the application: additions and updates. An addition occurs when the user inserts a new feature into the map. An update occurs when a user selects an existing feature and modifies its attributes. Thus, users can click on the feature of interest in the map to move it or alter its attributes, or create new features using the editor template. 


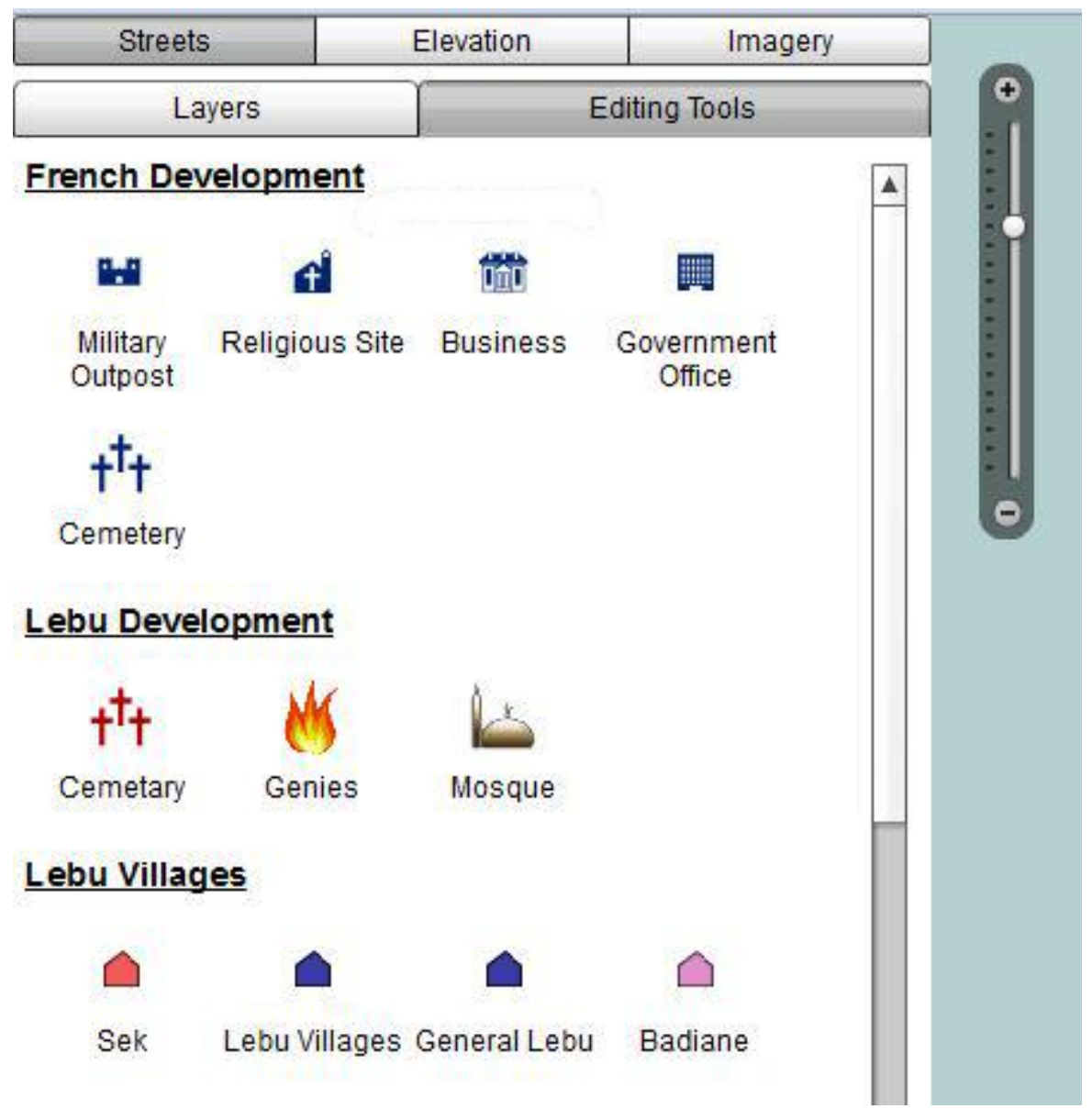

Figure 5-8 Editor Template

\subsection{User-Contributed Data Review}

Because users are able to contribute edits through the web application, there must be a method in place to review those edits. An ArcMap document was created for reviewing the user-contributed changes. It contains the feature classes from both the DEFAULT and WEBEDITING databases. The Versioning toolbar needs to be active in the map document. On the versioning toolbar, there is a button called Version Changes (Figure 5-9).

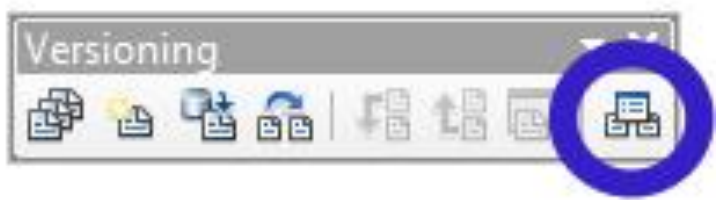

Figure 5-9 Versioning Toolbar and Version Changes Button

With the WEBEDITING version selected in the table of contents, the Version Changes tool shows all the differences between the two versions (Figure 5-10). 


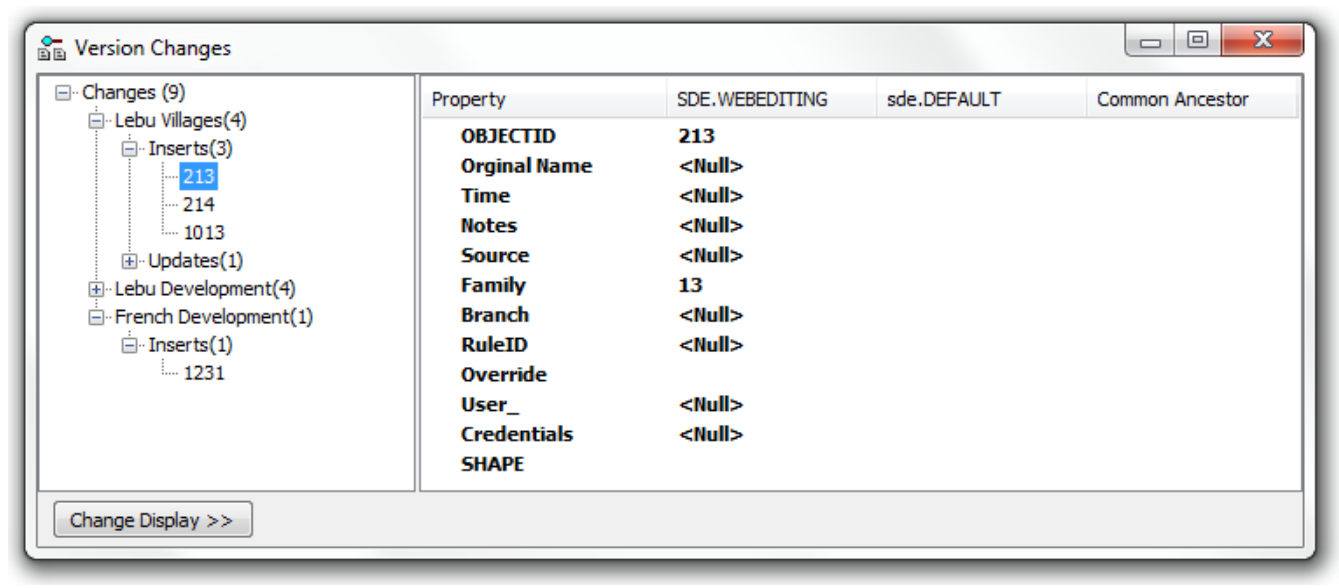

Figure 5-10 Version Changes Tool

It is up to the client to review the data and make the final decision on which contributions are valid. Users are prompted to include a citation or source of the data so that their contributions can be easily confirmed. If users do not include this information, the contribution can either be included or discarded at the discretion of the client.

The process of discarding edits is not particularly straightforward. In ArcMap, there is not a direct procedure for rejecting some edits from a version while including others. The best way to remove an addition is to delete it through an editing session in ArcMap, which is activated by selecting the Editor toolbar. Updating feature attributes and changing feature locations can be completed in a similar fashion.

Once the contributions have been reviewed, two final steps must be completed before they are included in the main database. First, the data needs to be reconciled; this is done by clicking the Reconcile button on the Versioning toolbar while in an editing session. Reconciling is a required part of the process of posting the data to the main database that checks for conflicts between edits. Because the data from this version will only being edited from the web, there should never be conflicts. Therefore, the default settings on the Reconcile dialog should be left unchanged. The last step is to post the data to the main database; this is accomplished by clicking the Post button on the Versioning toolbar. This will detect all the differences between the WEBEDIT version and include them in the DEFAULT version of the database. At this point, the two versions will be exactly the same, until a user on the web makes new edits.

\subsection{Summary}

This chapter discussed the process of implementing the web application for the client. This included the map preparation, data migration, publishing the map services, and the development of the web application using the ArcGIS API for Flex. It also described the capabilities of the web application for both browsing and editing the data. The chapter concluded with a discussion of the workflow for reviewing the user contributed data. 


\section{Chapter 6 - Use Cases}

There are two primary uses for this application. First, the application provides a way to share information about the Lebu culture with others. Second, it provides a way to collect user-contributed data to improve the existing data. This chapter presents two use cases: one for an African History researcher who is interested in learning more about the Lebu (Section 6.1), and one for a history professor who would like to share information about the Lebu, to be included in the web application (Section 6.2).

\subsection{Use Case 1: Browsing the Data}

Suppose an African History researcher has studied other cultures in West Africa. During his research on a specific region, he became exposed to the Lebu, but had not studied them in detail. He is very interested in using this web application to learn more about the distribution of the Lebu villages.

Upon opening the web application, the user first sees a street map of the city of Dakar (Figure 6-1). This is the initial extent because it was the last stop in the migration for many of the Lebu families, prior to being driven out by the French settlers, and there is a high concentration of villages here. The Lebu village sites, Lebu development, and French development layers are all initially active.

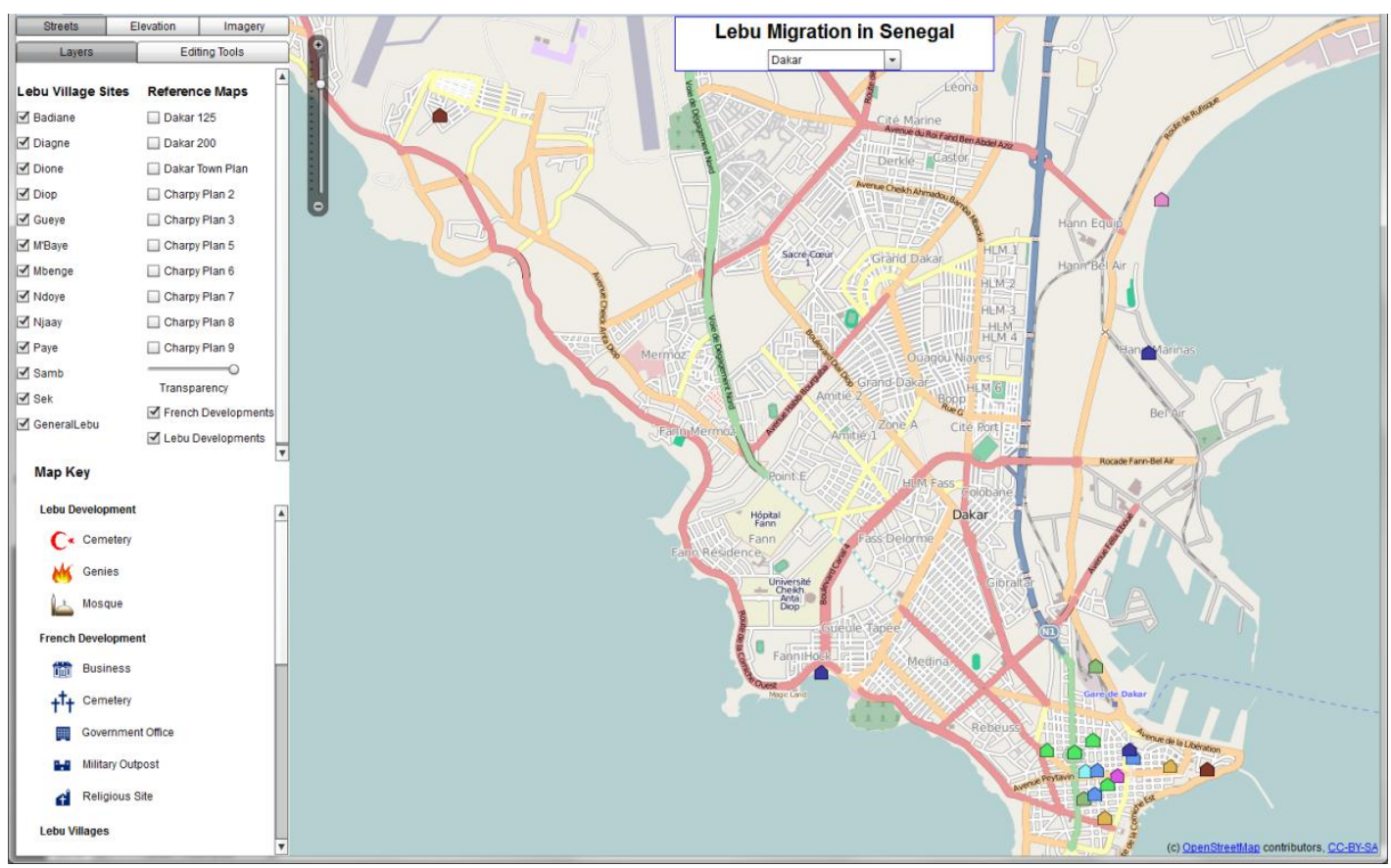

Figure 6-1 Initial Application View

To learn more about each feature on the map, he only needs to hover over the feature with his cursor. A ToolTip will activate and display all the attributes that are recorded for that feature. The fields that could be displayed for the villages are the name, notes, 
and data source or citation for the village. If any of those fields have no records, they are excluded from the ToolTip.

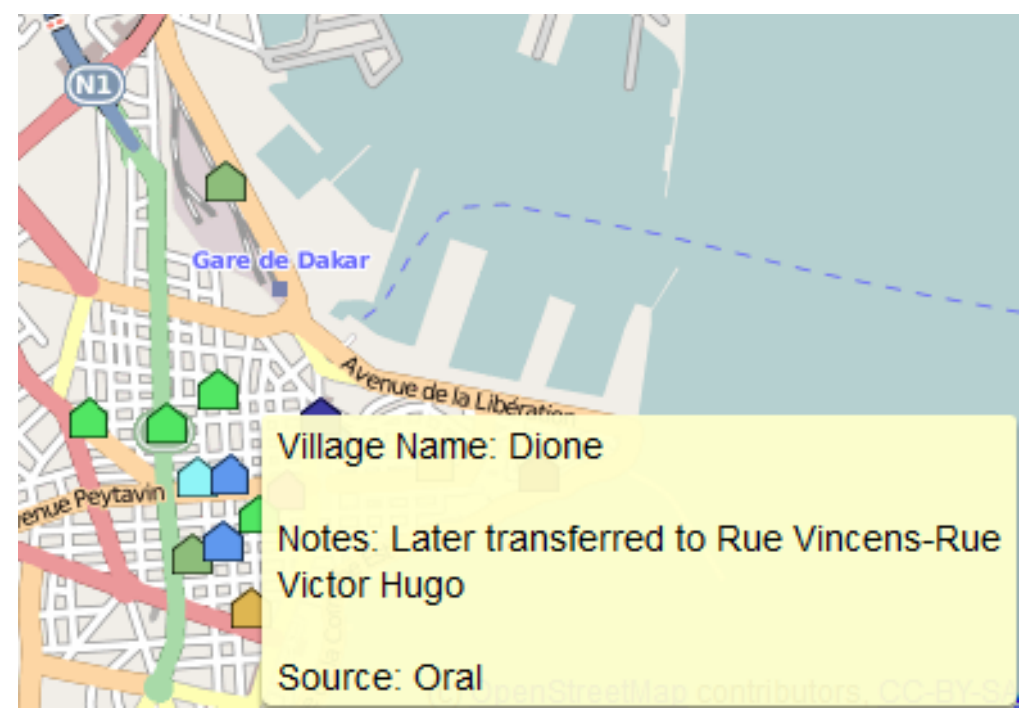

Figure 6-2 ToolTip of a Lebu Village

If he wishes to see only the villages from a particular a set of the Lebu families, he can use the check boxes to turn off all layers, except for the layers he is interested in. On the left side of the application, there are tabs for the Layers and Editing Tools. The Layer tab is active by default, and it contains all the layers available to view on the map. There are two column headers, one for Lebu Village Sites, and one for Reference Maps (Figure 6-3). Underneath the Lebu Village Site header, there are checkboxes with the names of all the Lebu families. By default, they are all active, but the user can uncheck any of them to remove them from the map. This enables him to view any set of families he wishes. 


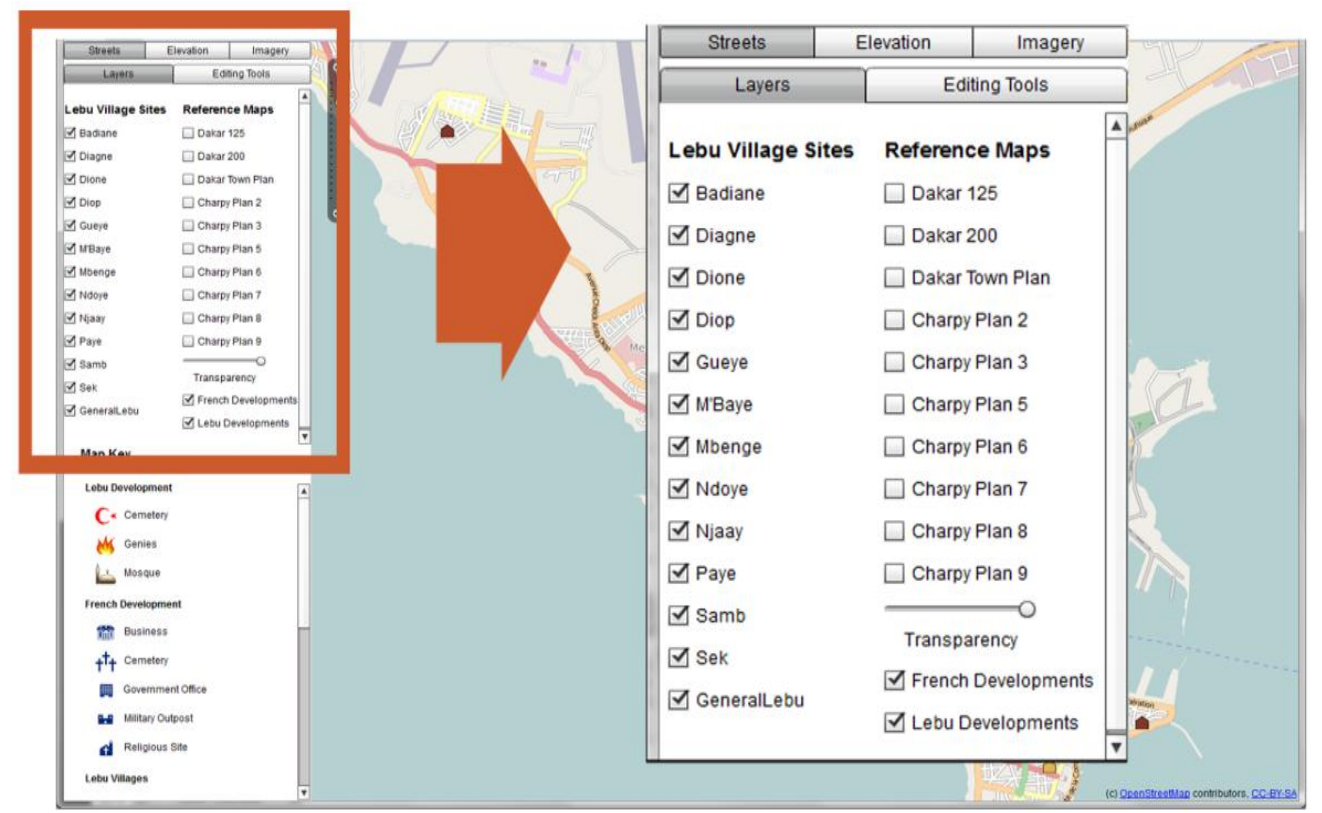

Figure 6-3 Lebu Family Selection

In addition to the village sites, the researcher can also activate and deactivate the layers for the French developments and Lebu developments. The controls to do that are also in the Layers frame, beneath the Reference Maps title (Figure 6-4). Those layers also have ToolTips that display the attributes of the feature. 


\begin{tabular}{|c|c|c|c|}
\hline Streets & evation & Imagery & \\
\hline Layers & \multicolumn{3}{|c|}{ Editing Tools } \\
\hline Lebu Village Sites & \multicolumn{2}{|c|}{ Reference Maps } & $\Delta$ \\
\hline$\checkmark$ Badiane & \multicolumn{2}{|c|}{$\square$ Dakar 125} & \\
\hline$\nabla$ Diagne & \multicolumn{2}{|c|}{$\square$ Dakar 200} & \\
\hline$\square$ Dione & \multicolumn{3}{|c|}{$\square$ Dakar Town Plan } \\
\hline$\nabla$ Diop & \multicolumn{3}{|c|}{$\square$ Charpy Plan 2} \\
\hline$\checkmark$ Gueye & \multicolumn{3}{|c|}{$\square$ Charpy Plan 3} \\
\hline$\checkmark$ M'Baye & \multicolumn{3}{|c|}{$\square$ Charpy Plan 5} \\
\hline$\nabla$ Mbenge & \multicolumn{3}{|c|}{$\square$ Charpy Plan 6} \\
\hline$\checkmark$ Ndoye & \multicolumn{3}{|c|}{$\square$ Charpy Plan 7} \\
\hline$\square$ Njaay & \multicolumn{3}{|c|}{$\square$ Charpy Plan 8} \\
\hline$\checkmark$ Paye & \multicolumn{3}{|c|}{$\square$ Charpy Plan 9} \\
\hline$\square$ Samb & \multicolumn{3}{|c|}{$\longrightarrow 0$} \\
\hline 110 & \multicolumn{3}{|c|}{ Transparency } \\
\hline & \multirow{2}{*}{\multicolumn{3}{|c|}{$\begin{array}{l}\checkmark \text { French Developments } \\
\square \text { Lebu Developments }\end{array}$}} \\
\hline$\checkmark$ GeneralLebu & & & \\
\hline
\end{tabular}

Figure 6-4 Lebu and French Developments

This application also has a selection of reference maps that he can overlay above the basemap and under the Lebu villages and developments. There are two US Army Map Service maps from 1942 and eight French planning maps from the $19^{\text {th }}$ century. These are not active by default, but they can be activated using the checkboxes from the Layers tab, as seen in Figure 6-5. In addition, a slider allows him to apply a transparency to the map overlay, so it can be compared with one of the basemaps. 


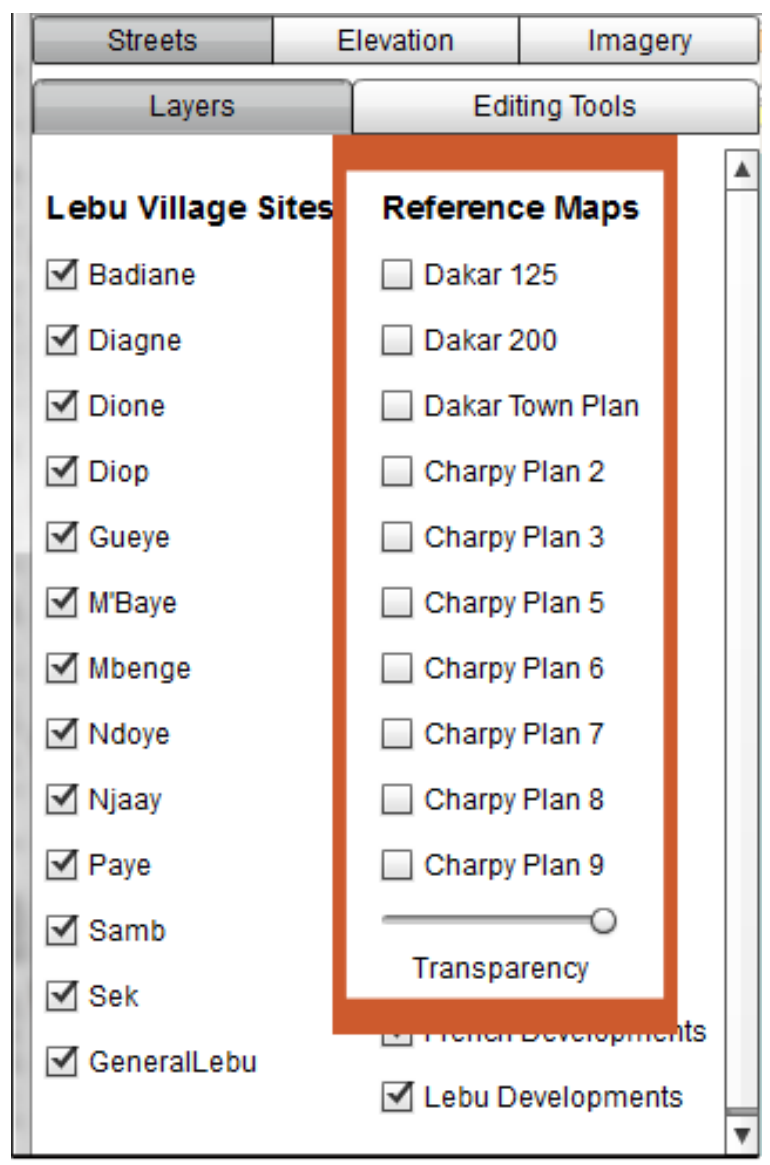

Figure 6-5 Reference Maps

Another way that the researcher can change the view of the map is to switch to a different basemap. There are three basemaps available to choose from in this application: streets, shaded relief, and aerial imagery. They can be switched by selecting the buttons above the Layers tab as seen in Figure 6-6. These basemaps were selected for various reasons. The street map provides a reference to compare the historical data with the current layout of the area. The shaded relief gives the user a reference to the topography of the region, and the aerial imagery allows the user to see the features of the earth. 


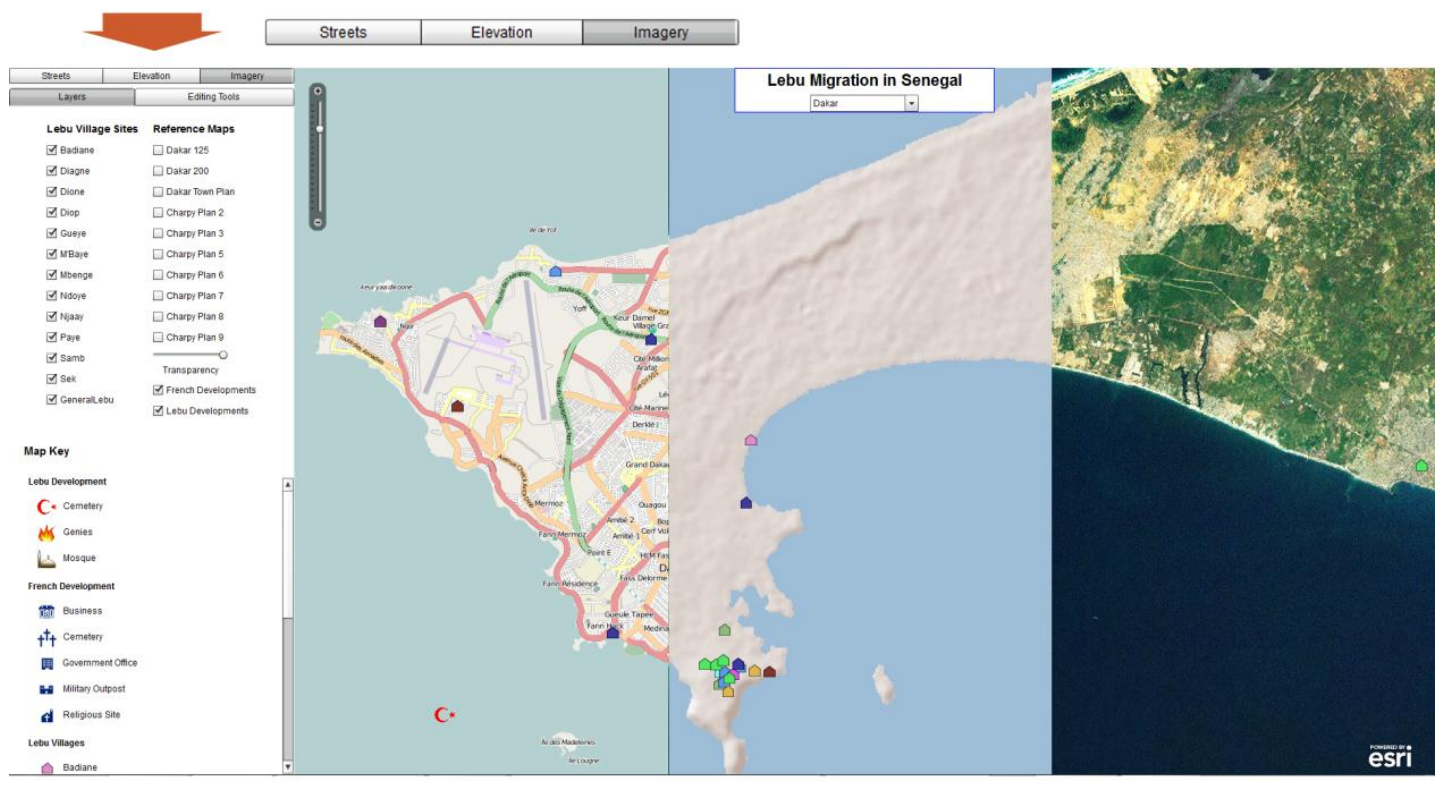

Figure 6-6 Basemap Selections

The final component, located beneath the layers checkboxes, is the map key. This provides users with a description of all the symbols on the map (Figure 6-7).

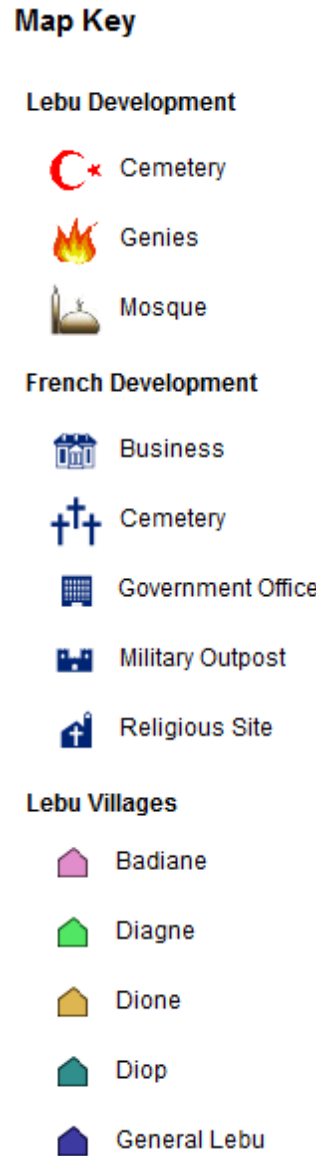

Figure 6-7 Map Key 
In general, the history researcher can use this web map to learn more about the Lebu villages in Senegal along their migration to the Cap-Vert Peninsula.

\subsection{Use Case 2: Editing the Data}

A history professor has been studying the Lebu migration when she comes across this web application. She has already done much of data collection, and thinks it would be useful to add her data to this application, so it can be displayed graphically. Because of the editing capabilities in this application, the scholar is able to insert any new data points for Lebu villages, Lebu developments, or French developments. She is also able to edit the attributes of any of the existing points.

When ready to edit the data on the web map, the professor needs to click the Editing Tools tab, next to the Layers tab. This brings her to the Editing Tools tab, where she will start making the edits. At the top of the editing window, as seen in Figure 6-8, there is an introduction to the editing capabilities. It informs the professor that the editing options include inserting new data points and editing existing features. Additionally, when she makes an edit, she is prompted to provide a data source or citation so that it can be verified. If a source is not available, the user is prompted to supply the necessary contact information. Once the user is familiar with the introduction, she will click the Start Editing button to activate an edit session.

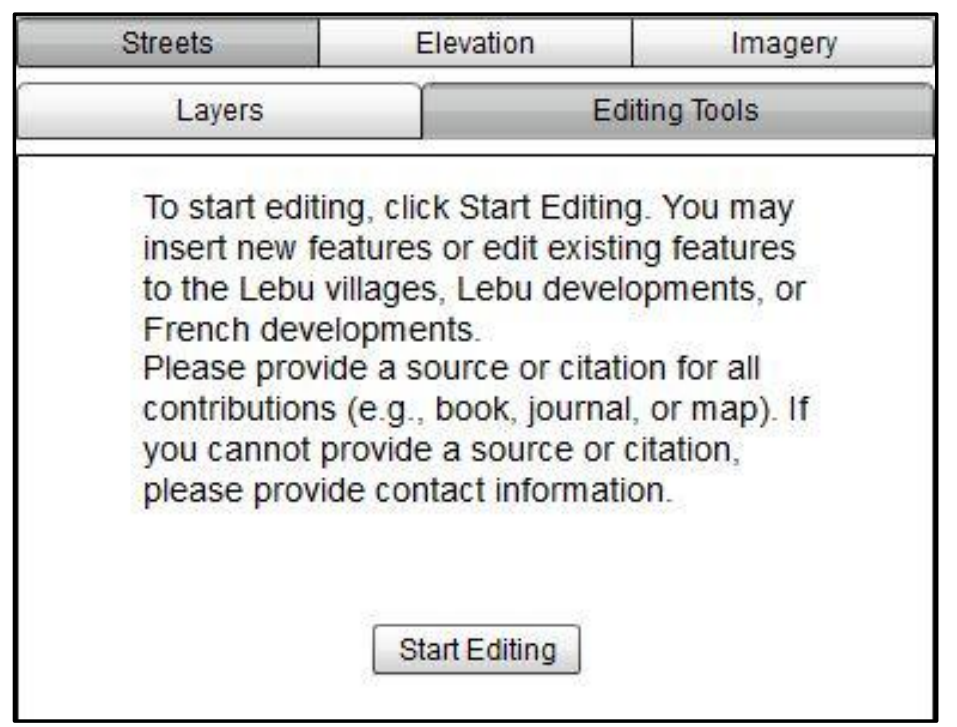

\section{Figure 6-8 Editing Window}

Once the researcher has begun an editing session, she is presented with a template of features that can be inserted into the map (Figure 6-9). This is a complete list of the features that are available to be inserted. 


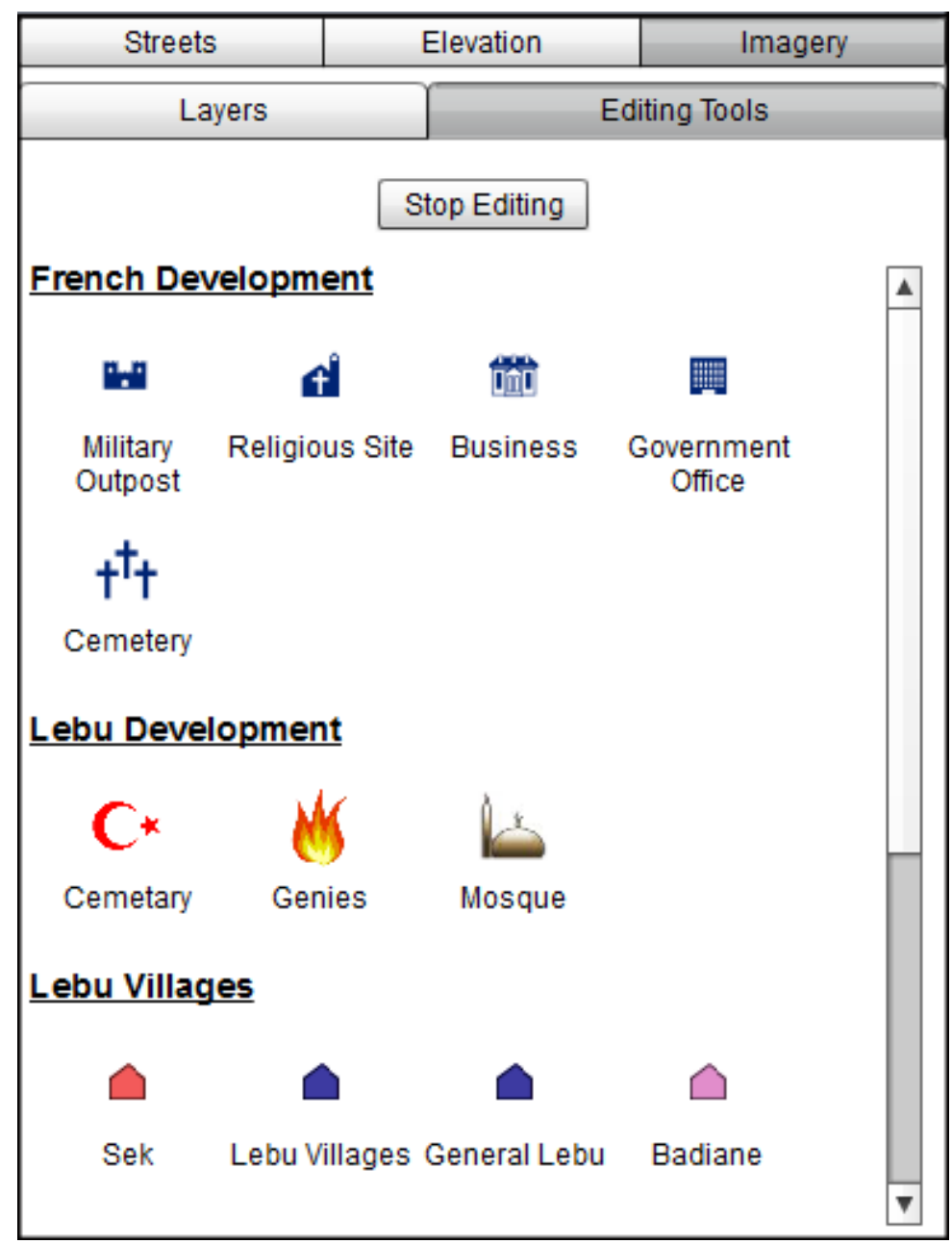

Figure 6-9 Editing Template

To insert a feature, she clicks on the type of feature she would like to insert from the template, and then click on the map where that feature belongs. In this example, the scholar has added a mosque to the map. Once the feature has been inserted, a window opens, prompting her to enter the attributes of that feature (Figure 6-10). She has included that the data source is the Map of the Village of Dakar from 1853, but did not include any other details. It is important for the user to enter the attributes as completely as possible. There is no need for the user to save the edits, as changes are saved automatically once an edit is executed. 


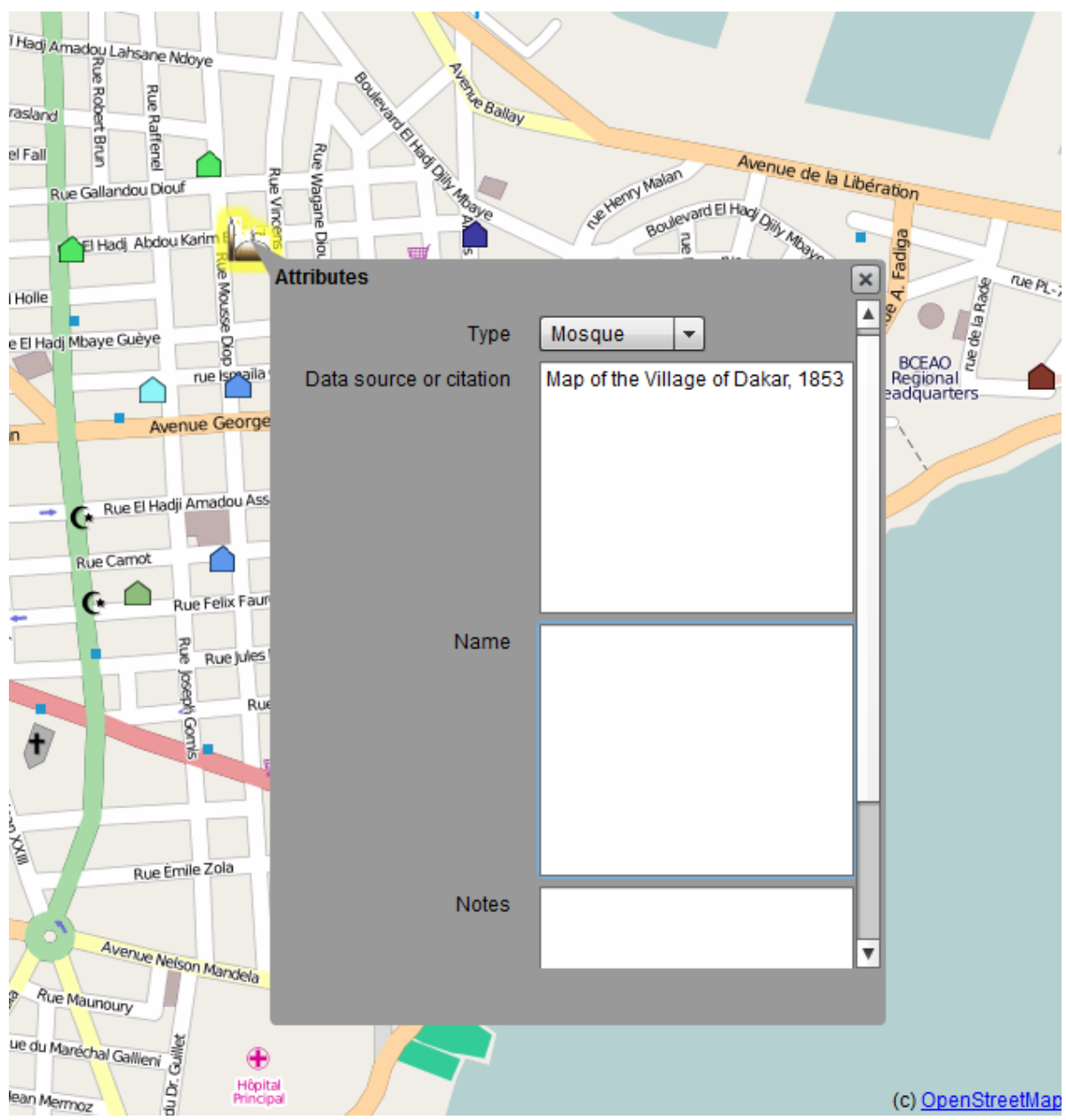

Figure 6-10 Attribute Editor

It is also possible that a feature already exists, but some attribute is incorrect, or it needs to be moved. In this case, the user just needs to click on the feature in the map to select it. The attribute editor will open, and the attributes can be changed. Alternately, the user can click and hold on the feature to allow changes to its geometry.

Once the professor is finished inserting or editing the features, she can click on the Stop Editing button above the editor template to return to browsing mode. Once she exits editing mode, the editing layer will be deactivated, and the DEFAULT version of the data will be displayed. Her edits will not appear in the browsing mode of the application until they have been reviewed for accuracy and accepted into the DEFAULT version.

However, if she wants to review her edits, she can have access to her edits in the editing mode and continue to make changes.

\subsection{Summary}

This chapter detailed two use cases for using this application. The first was a history researcher familiar with West African history, but not with the Lebu migration. He could use this application to learn more about the distribution of the Lebu villages along their migration. The second use case was a history professor who was familiar with the Lebu, 
and also had collected data about them. She could have used this application to insert her data to the map, so the database could be improved. Once her contributions are reviewed for accuracy, they would be included in the main database. 


\section{Chapter 7 - Conclusions and Future Work}

The goals of this project were to provide a visualization of the Lebu migration, create a way to share that information internationally, and collect user-contributed improvements and additions to the existing data. To accomplish these goals, the client's data were organized in an Esri ArcSDE geodatabase. Large-format paper maps were created showing the migration of the Lebu. A web map application was created using the ArcGIS API for Flex to visualize the existing data and share it worldwide. Additionally, the web application enables users to contribute their knowledge by adding or editing the features in the web map. Finally, there is a process for the client to review the user contributions to determine what edits to incorporate in the main database.

Given that the project successfully addressed client's needs, several improvements can be completed in the future. First, the web application functionality could be enhanced. For example, additional work could be done with this data by creating a network dataset for the Lebu migration. This could help identify the lineage of the migration, to see if any merging or branching occurred within the Lebu families. The temporal changes of the Lebu villages and development could be incorporated into the web application. This was not possible to complete for this project because the temporal data was not available. If this application is used as intended, and temporal data is added by the users, a time slider could be added to the web application to filter for desired time periods.

Incorporation of climate into the visualization could also be added. At the time of this project, the only climate data available was extremely generalized, so it was not useful for analysis or visualization on a larger scale. If higher resolution historic climate data becomes available, that would be very useful for trying to identify a correlation between the climate and the migration. Combining this with temporal changes in migration and political data would present a very interesting visualization of the Lebu migration pattern.

Third, streamlining the user-contributed data review could also be achieved in the future. The current review process using the versioning tools in ArcGIS Desktop 10 allows the user to see all the edits made in a version, but it does not let a user reject only certain changes, without manually editing them. It would also be useful to be able to see all of the historical edits for a single feature. This is a limitation of the software, but that functionality could possibly be achieved programmatically.

The user review could also be improved if there were user accounts for editing the data in the web application. Implementing this was outside the scope of this project, but it could greatly improve the review process. This way, if a single editor were to sabotage the database, all the edits from that user could be discarded, and that username or IP address could be banned.

In summary, the project demonstrates that integrating technology, particularly web GIS, into a historical study not only allows us to visualize and analyze the historical migration data in a spatio-temporal context, but also facilitate knowledge sharing within the research community. 



\section{Works Cited}

Angrand, A. P. (1946). Les Lébous de la Presqu'île du Cap-Vert. Dakar: E. Gensul. Arctur, D. (2004). Designing Geodatabases. Redlands: Esri Press.

Balandier, G., \& Mercier, P. (1952). Les Pêcheurs Lebou du Sénégal, particularisme et evolution. St. Louis: I.F.A.N.

Batty, M., Hudson-Smith, A., Crooks, A., \& Milton, R. (2010). Map mashups, Web 2.0 and the GIS revolution. Annals of GIS, 1-13.

Fu, P., \& Sun, J. (2011). Web GIS Principles and Applications. Redlands: Esri Press.

Glover, J. (2011). Unpublished manuscript.

Goodchild, M. (2007). Citizens and sensors: the world of volunteered geography. GeoJournal, 211-221.

Gregory, I. (2000). Longitudinal Analysis of Age- and Gender- Specific Migration Patterns in England and Wales A GIS- Based Approach. Social Science History, 24(3), 471 - 503.

Gregory, I. (2003). A Place in History: A Guide to using GIS in Historical Research. Eynsham, England: Oxbow Books.

Gregory, I., \& Ell, P. (2007). Historical GIS. Cambridge: Cambridge University Press.

Hirst, M. A. (1970). Tribal Migration in East Africa: A Review and Analysis. Geografiska Annaler, 153 - 164.

Hirst, M. A. (1976). A Markovian analysis of inter-regional migration in Uganda. Geografiska Annaler, 79-94.

Longley, P. A., Goodchild, F. M., Maguire, J. D., \& Rhind, W. D. (2005). Geographic Information Systems and Science. West Sussex: Wiley.

Massey, D. (2005). For Space. London: Sage.

Murugesan, S. (2007, July). Understanding Web 2.0. IT Pro, pp. 36-37.

Tang, W., \& Selwood, J. (2003). Connecting Our World. Redlands: ESRI Press.

Vlist, E., Ayers, D., \& Bruchez, A. (2007). Professional Web 2.0 Programming. Indianapolis: Wiley.

Zeiler, M. (2010). Modeling Our World. Redlands: Esri Press. 



\section{Appendix A. Web Map Application Code}

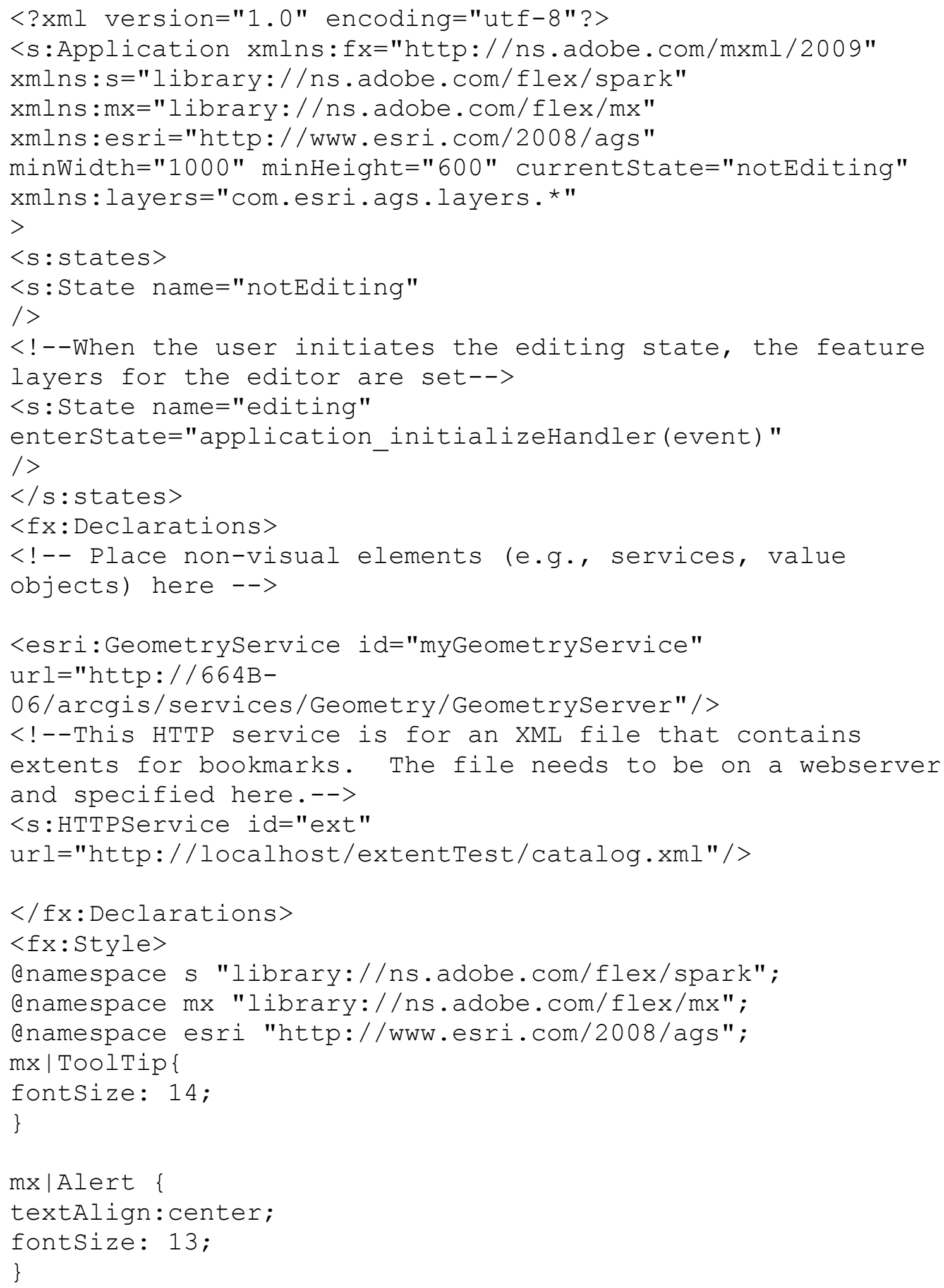




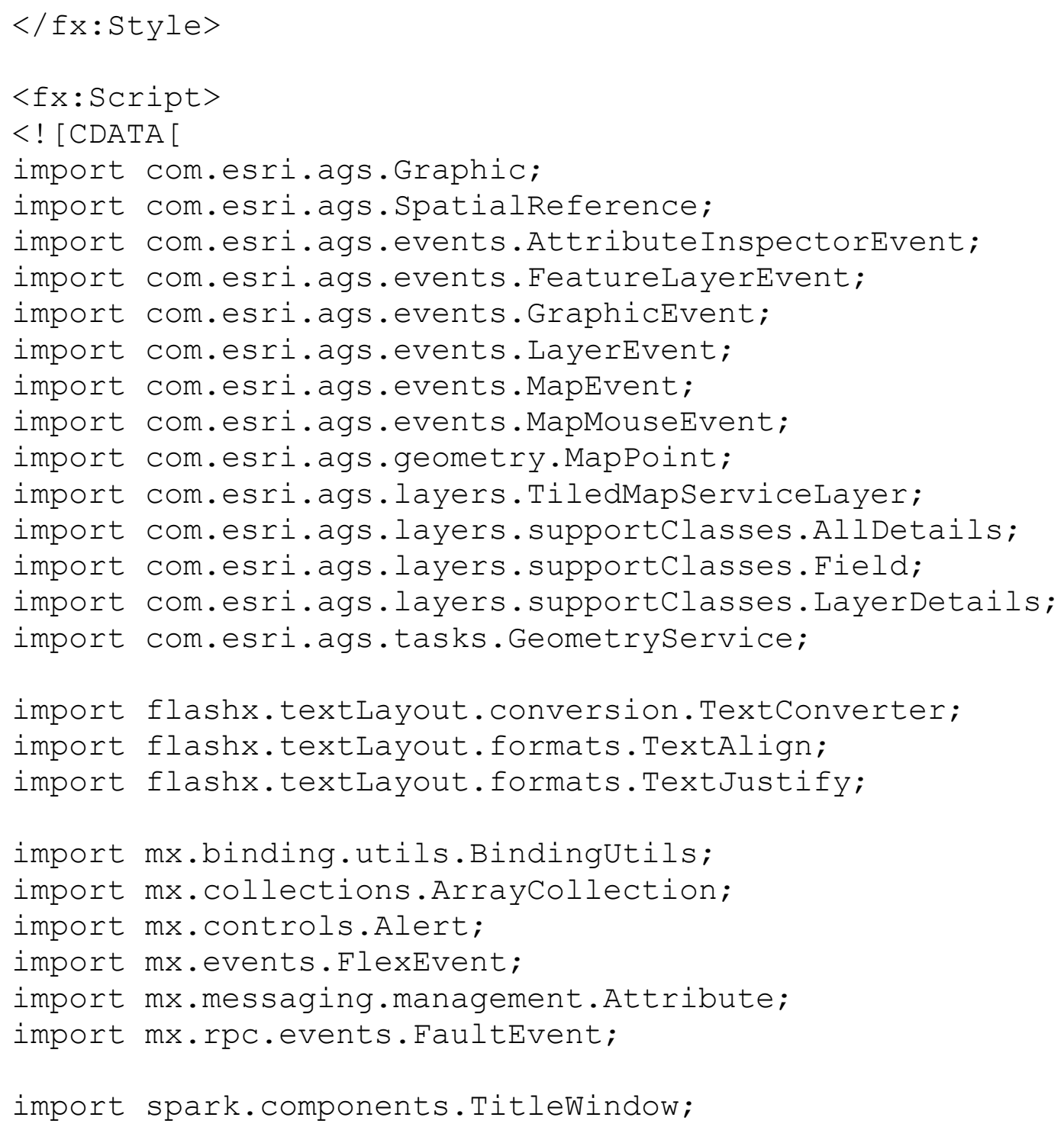




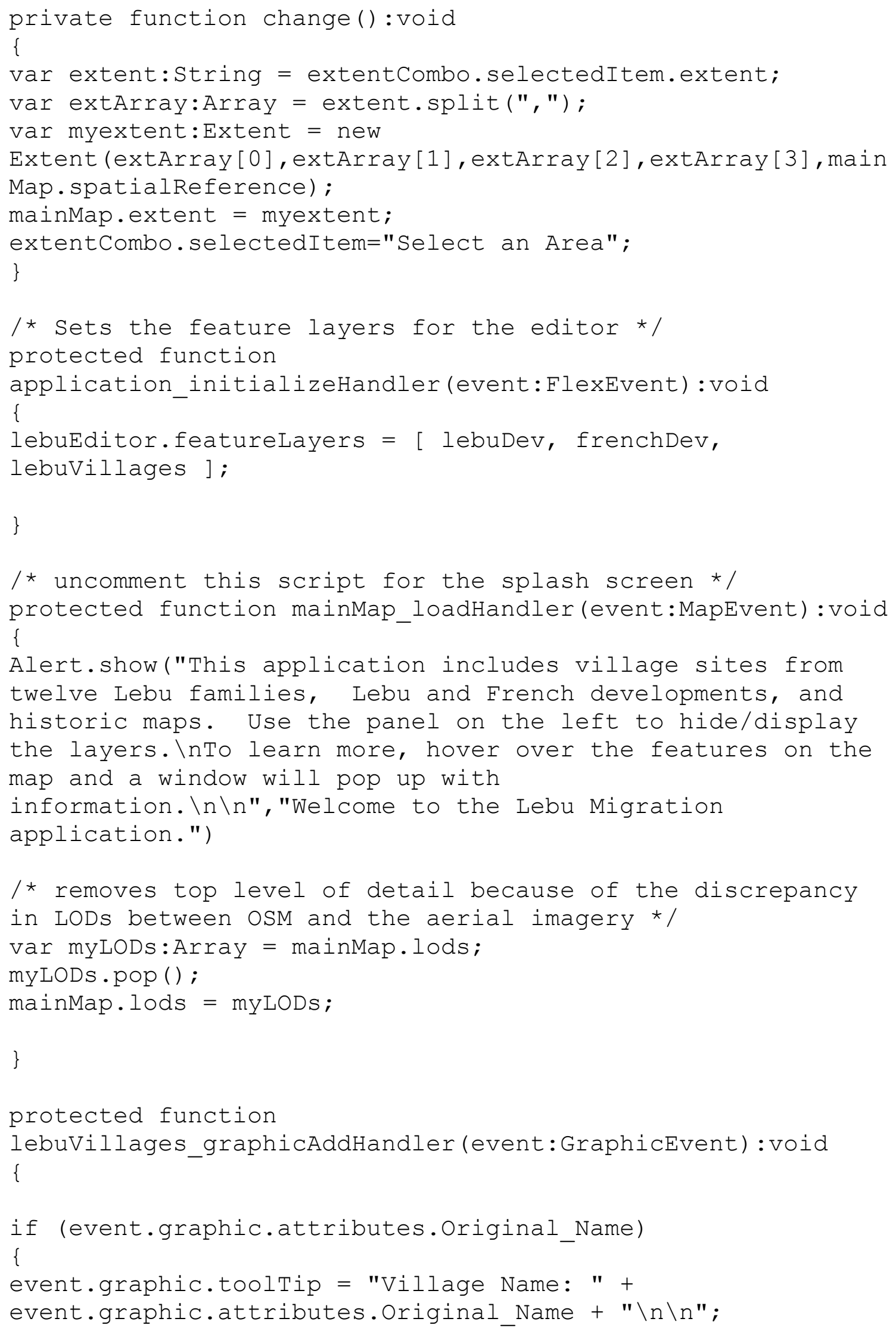




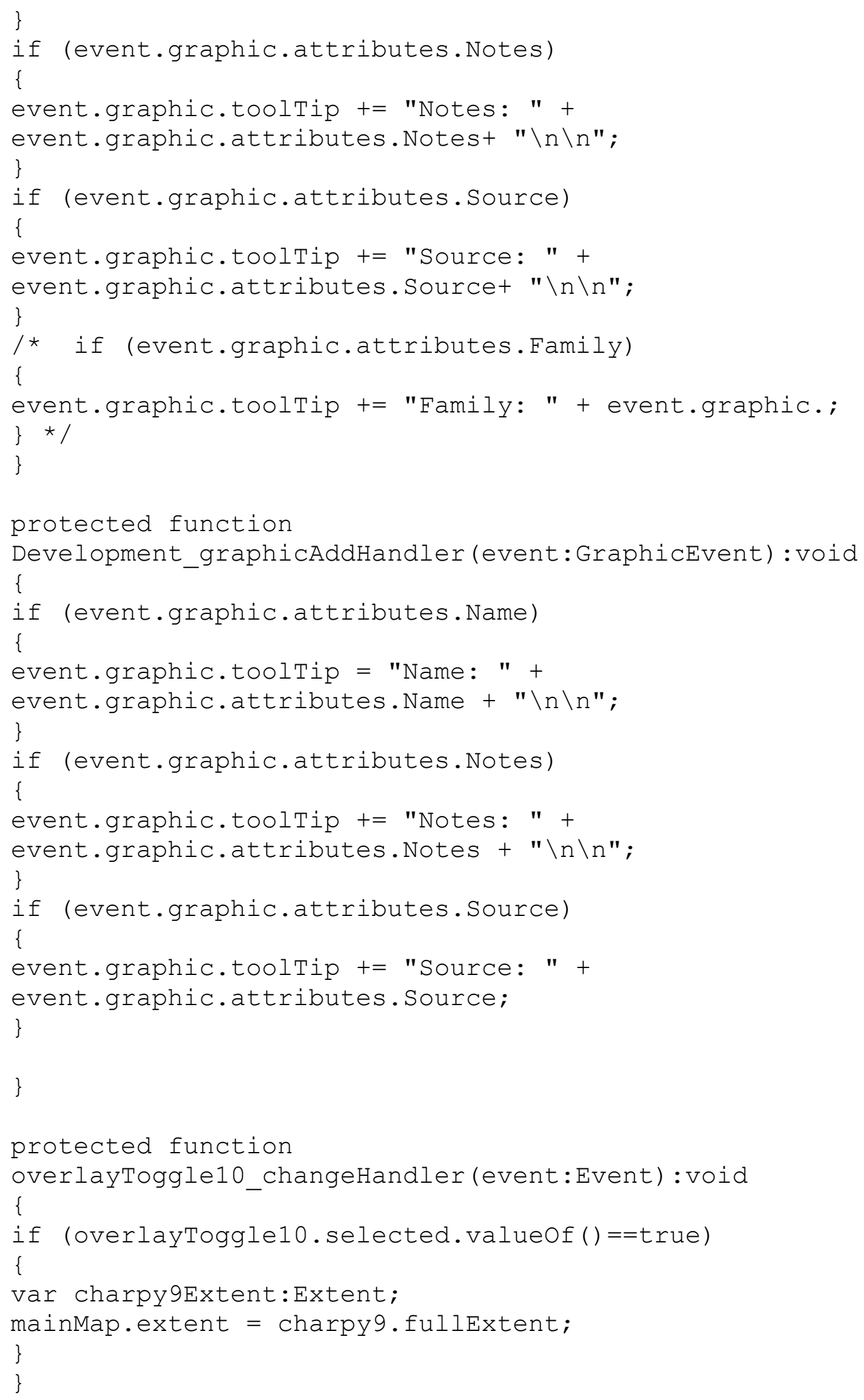




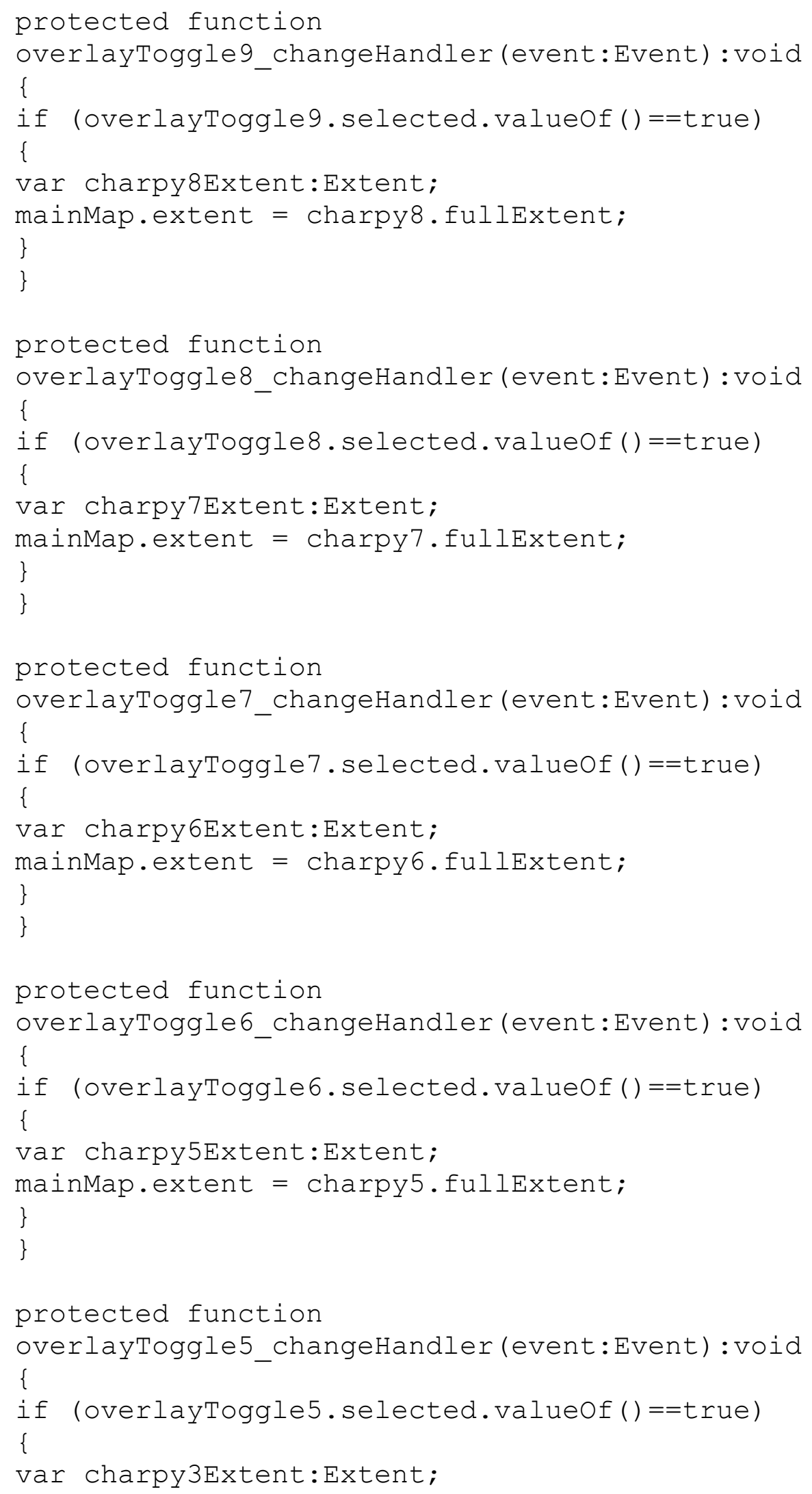




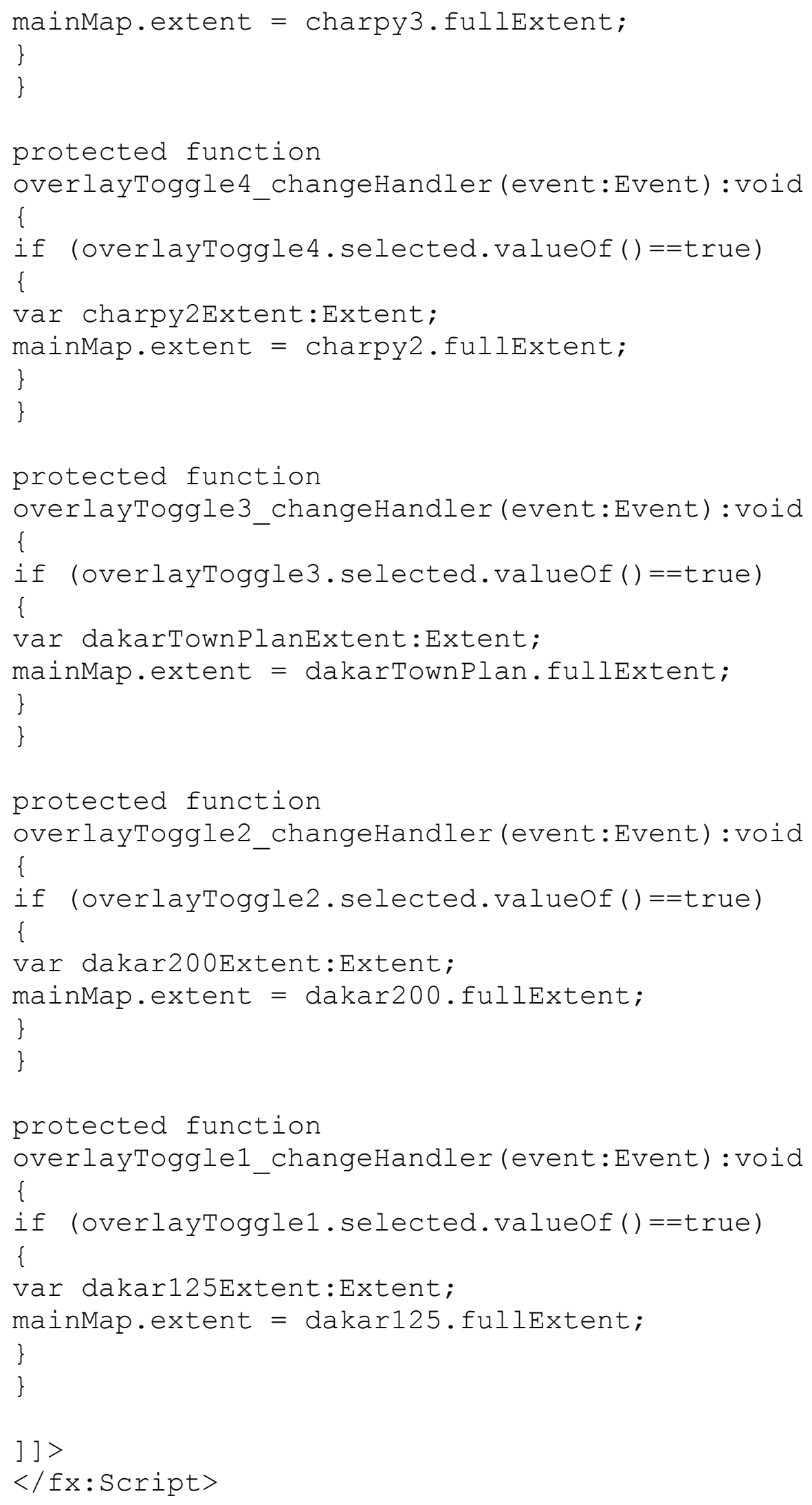




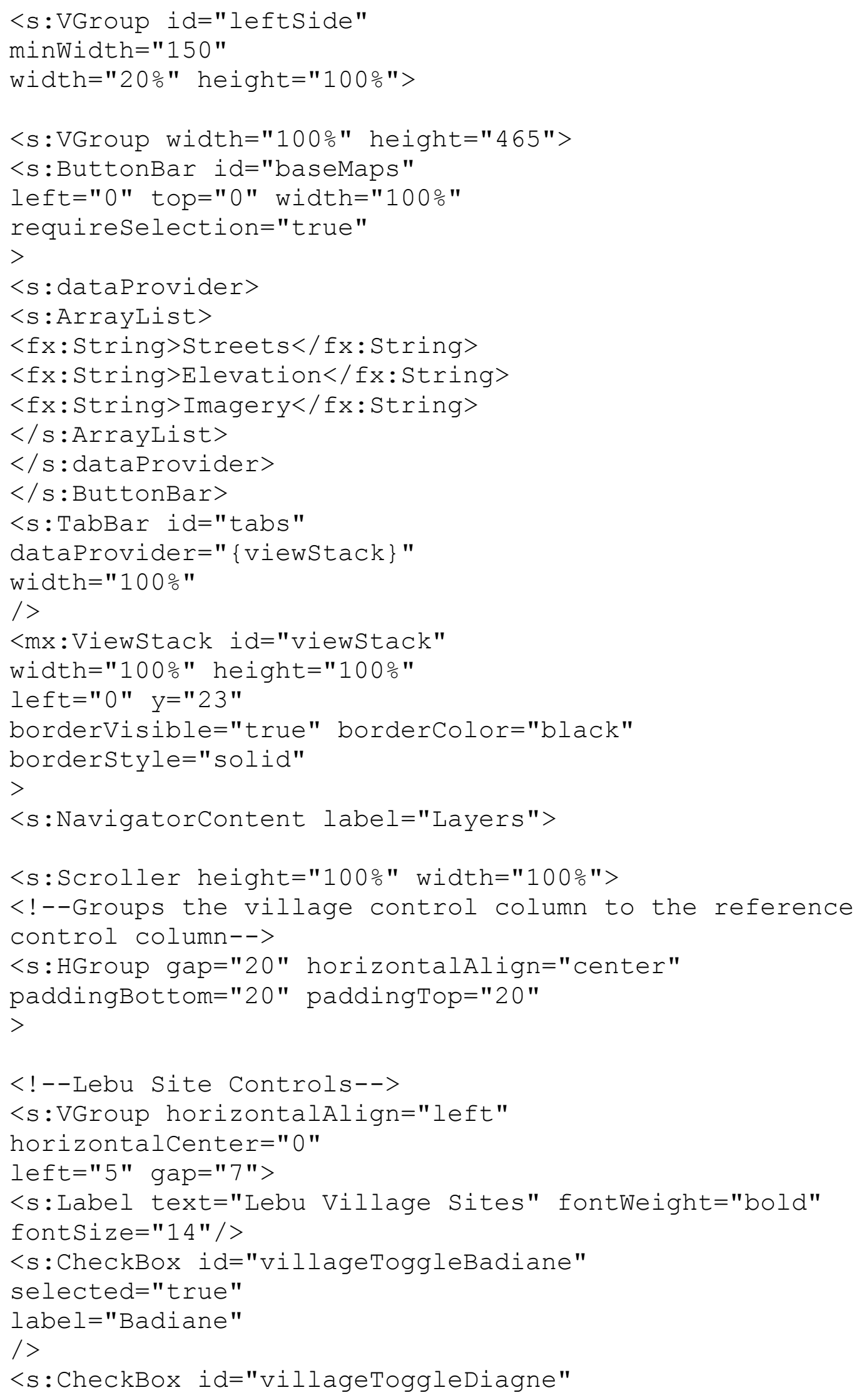




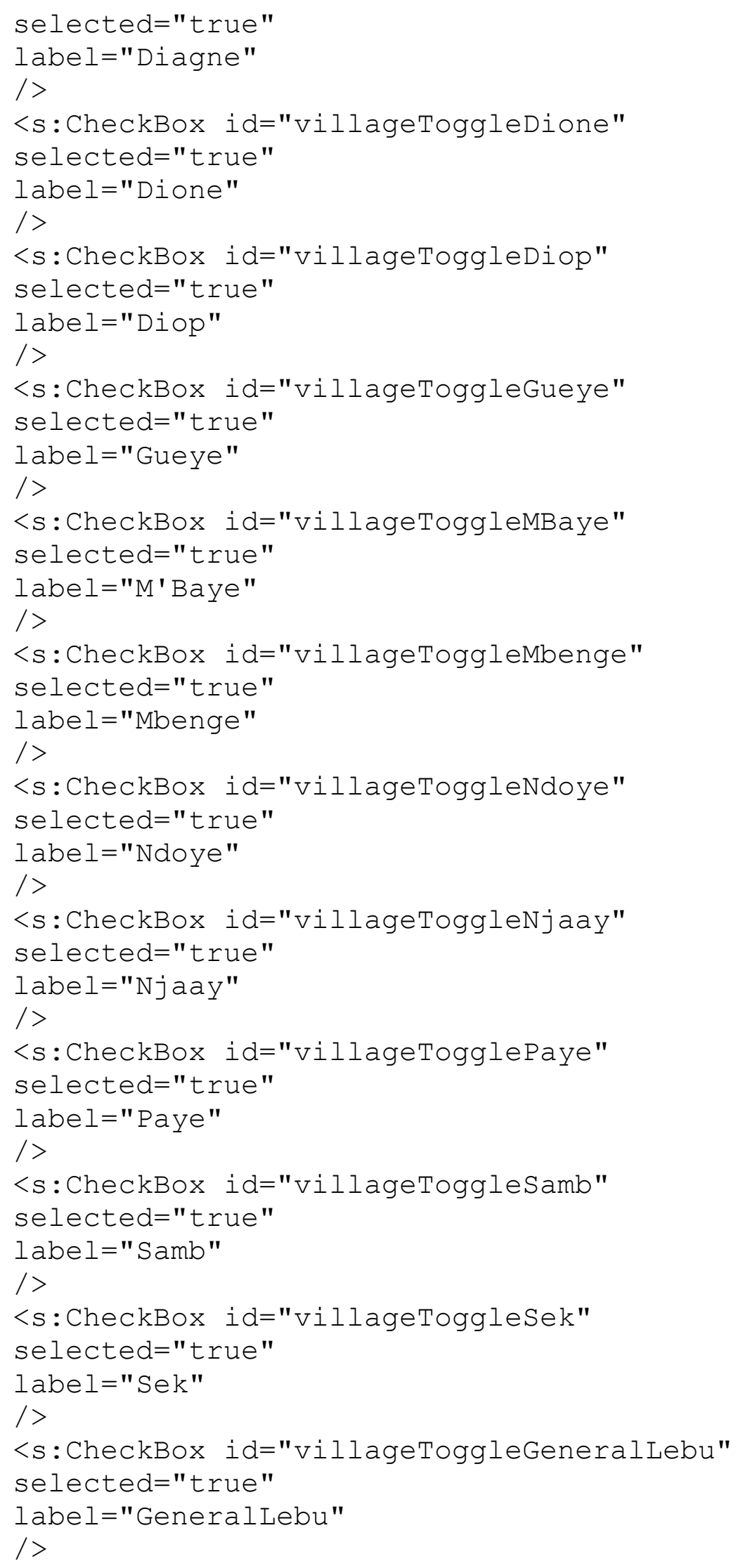




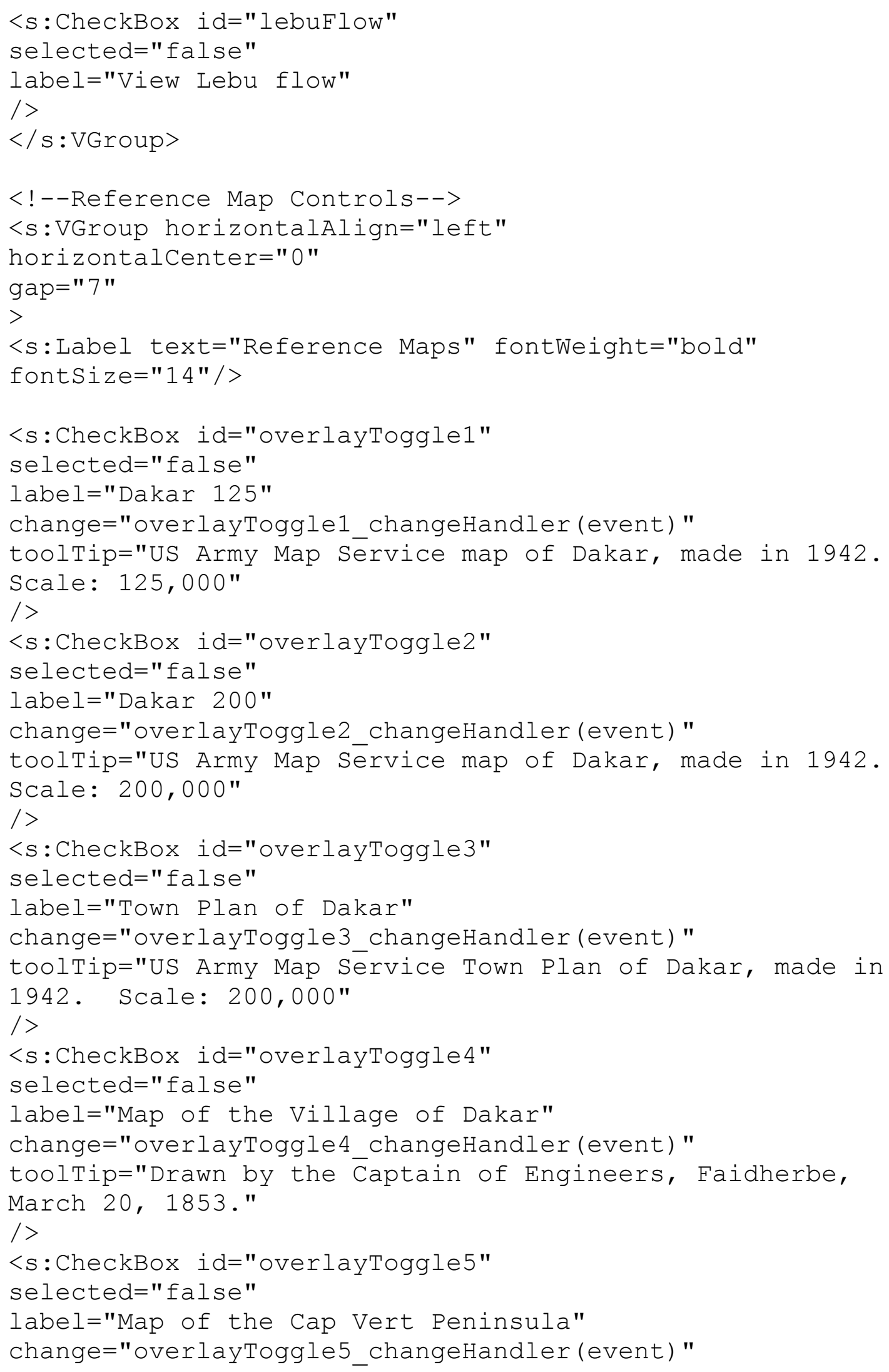




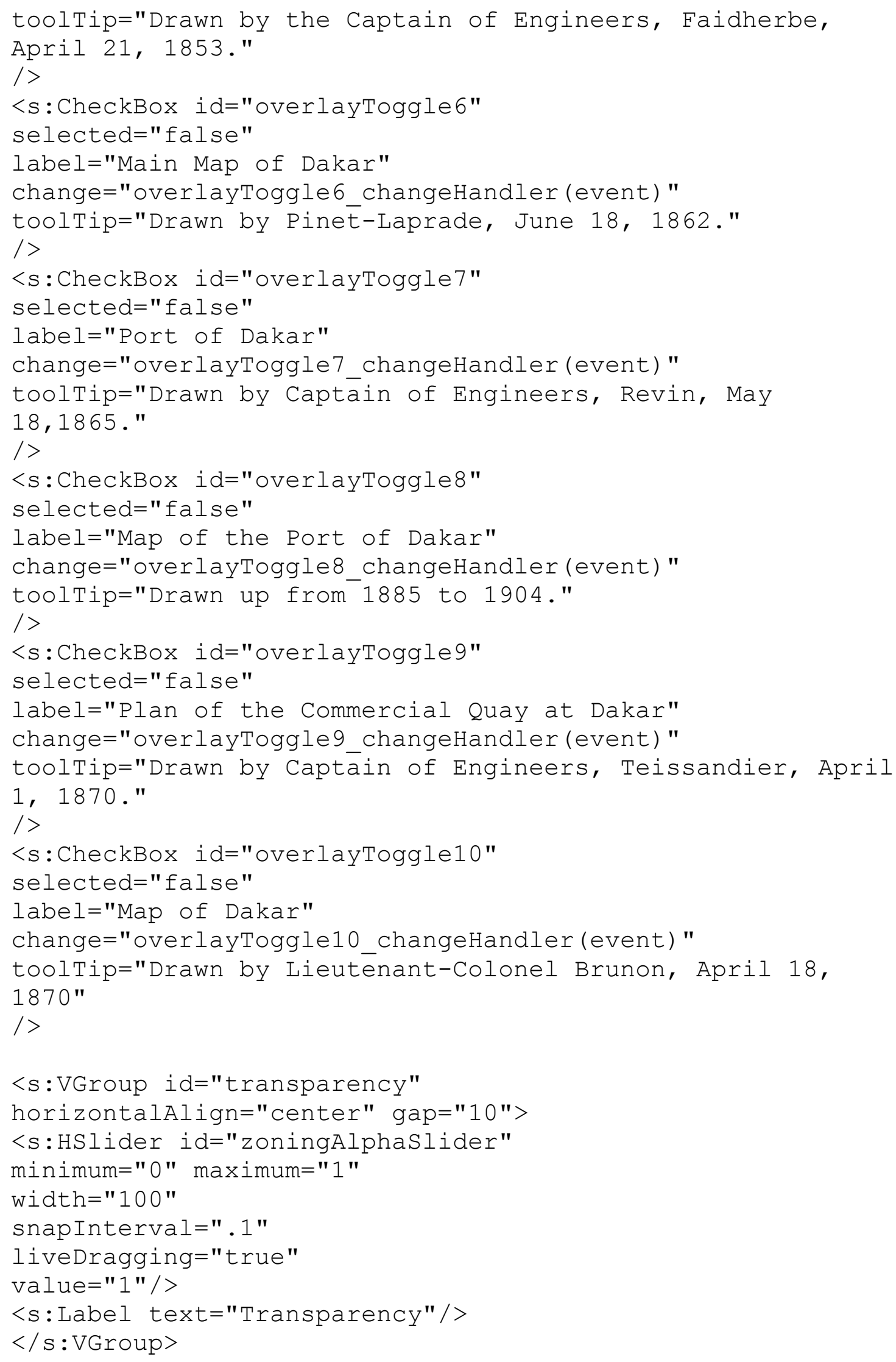




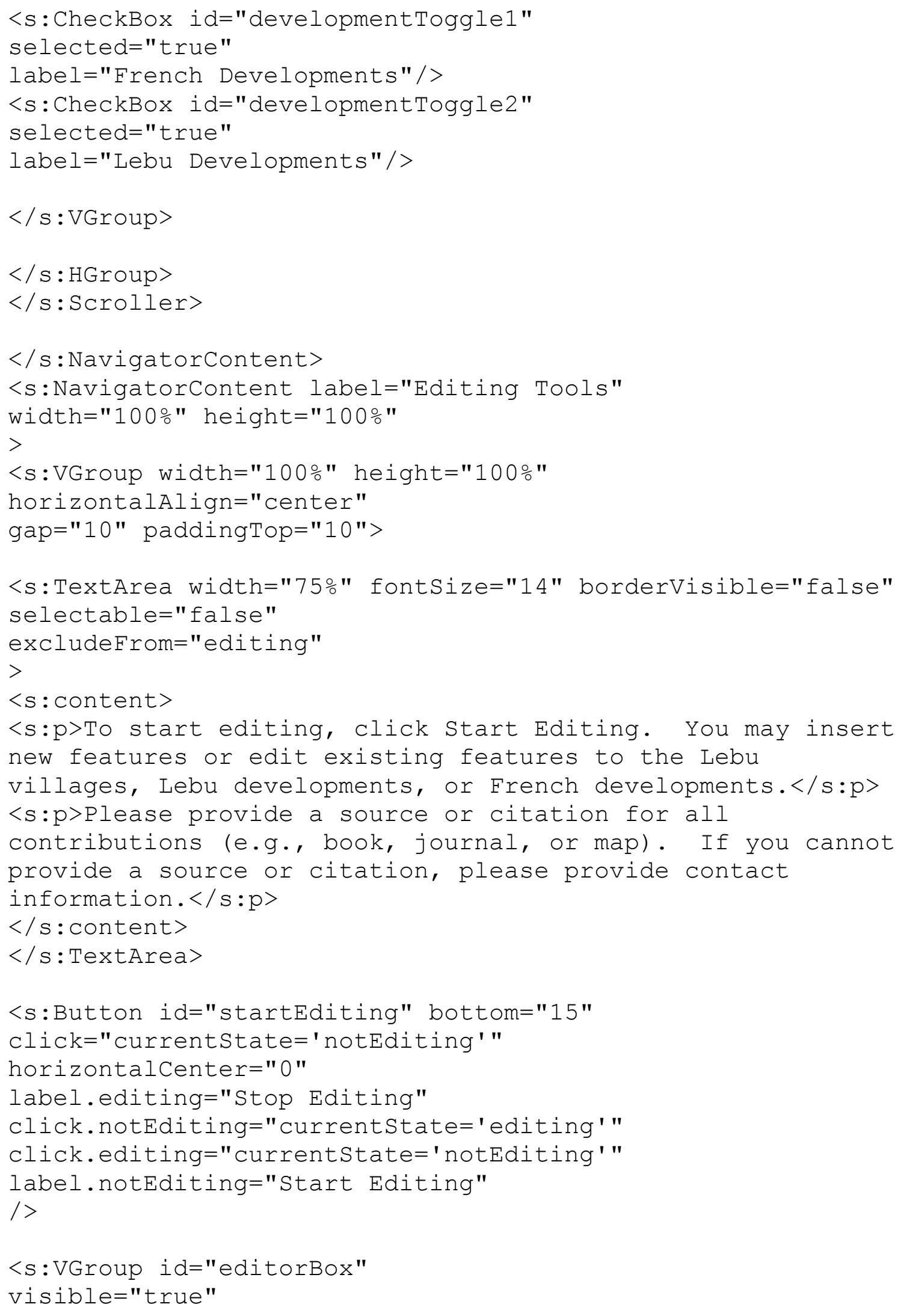




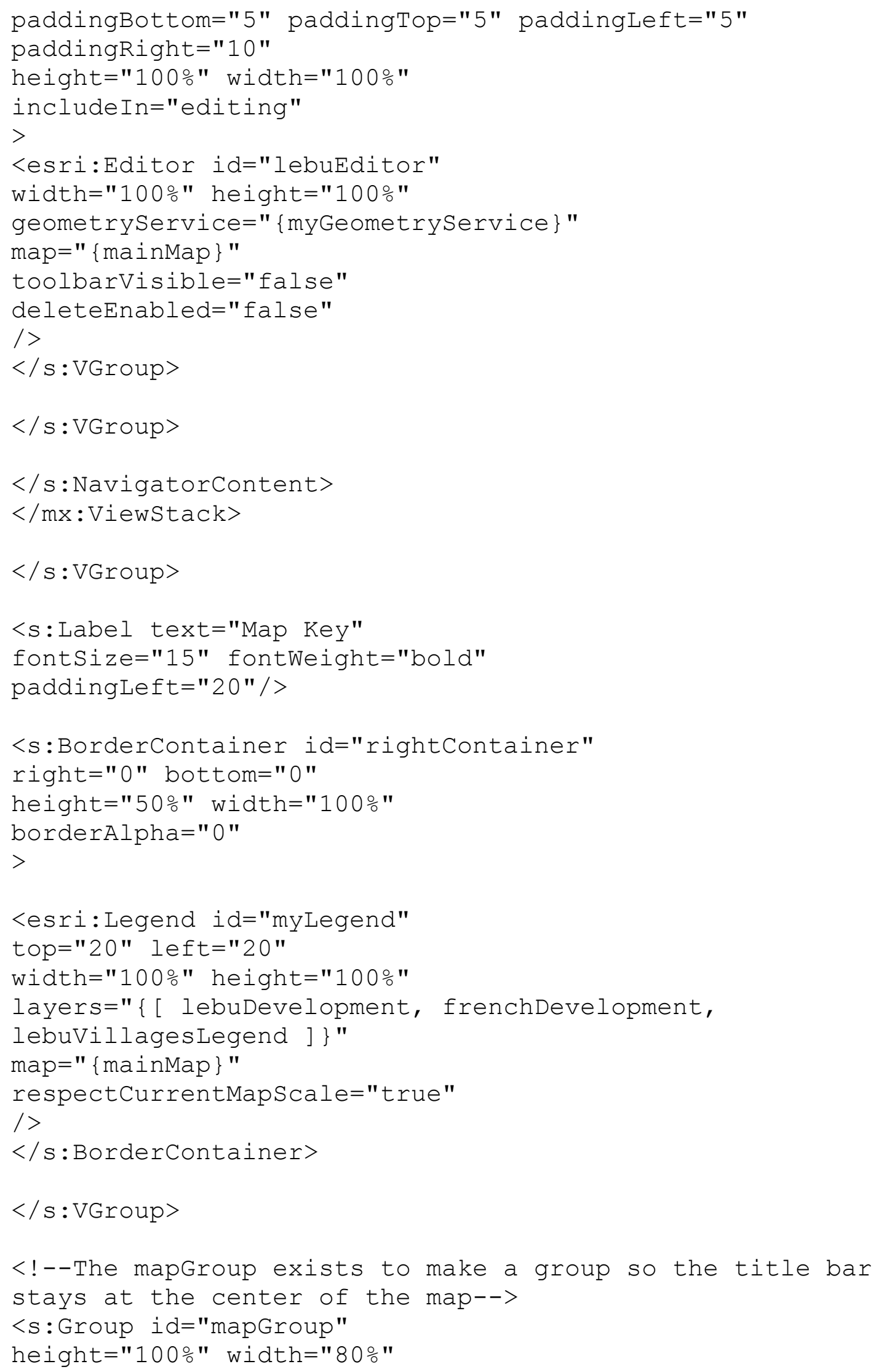




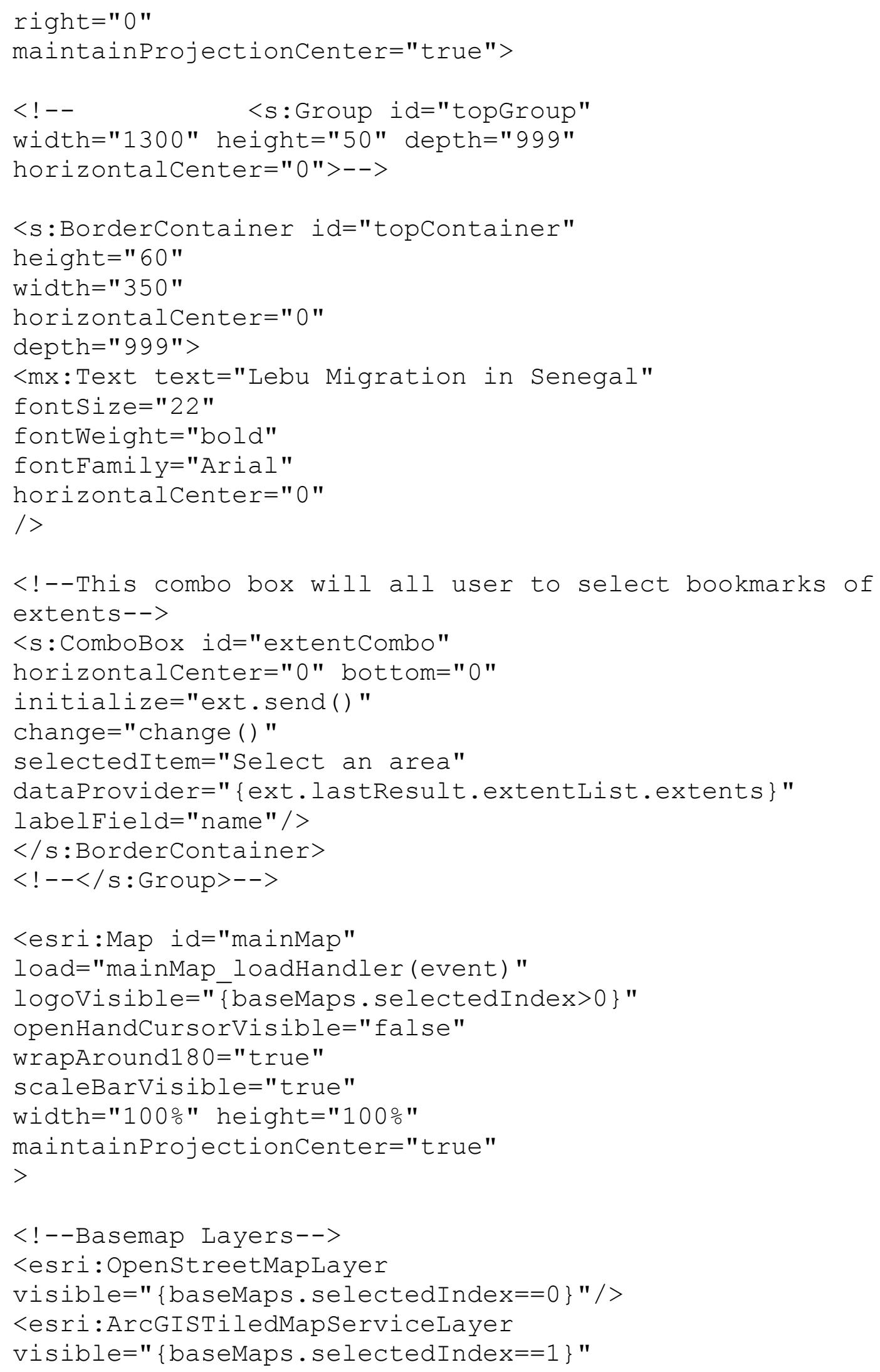


url="http://server.arcgisonline.com/ArcGIS/rest/services/Wo rld Shaded Relief/MapServer"

$\max \overline{\mathrm{S}} \mathrm{cale}=" \overline{7} 2224 " />$

<esri:ArcGISDynamicMapServiceLayer url="http://664b-

$06 /$ ArcGIS/rest/services/MIP/Africa_Ocean/MapServer"

visible=" $\{$ baseMaps. selectedIndex $=\overline{1}\}$ " / >

<esri:ArcGISTiledMapServicelayer id="imagery"

visible $=$ " $\{$ baseMaps. selectedIndex $==2\}$ "

url="http://server.arcgisonline.com/ArcGIS/rest/services/Wo rld Imagery/Mapserver"

$\max \overline{\mathrm{S}} \mathrm{cale}=" 4500 " />$

$<$ !--Reference maps-->

<esri:ArcGISDynamicMapServiceLayer id="dakar125"

url="http: / / 664b-

$06 /$ ArcGIS/rest/services/MIP/Dakar125/MapServer"

visible=" $\{$ overlayToggle1. selected $\} "$

alpha=" \{zoningAlphaslider.value $\}$

/ >

<esri:ArcGISDynamicMapServiceLayer id="dakar200"

url="http: / / $664 \mathrm{~b}-$

$06 /$ ArcGIS/rest/services/MIP/Dakar200/MapServer"

visible=" \{overlayToggle2. selected $\} "$

alpha $="\{$ zoningAlphaslider.value $\} "$

/ >

<esri:ArcGISDynamicMapServiceLayer id="dakarTownPlan"

url="http: / / 664b-

$06 /$ ArcGIS/rest/services/MIP/DakarTownPlan/MapServer"

visible=" \{overlayToggle3. selected $\} "$

alpha $="\{$ zoningAlphaSlider.value $\} "$

$1>$

<esri:ArcGISDynamicMapServicelayer id="charpy2"

url="http: / / 664b-

$06 /$ ArcGIS/rest/services/MIP/Plan2/MapServer"

visible=" \{overlayToggle4. selected $\}$ "

alpha=" $\{$ zoningAlphaslider.value $\} "$

I>

<esri:ArcGISDynamicMapServicelayer id="charpy3"

url="http: / / 664b-

$06 /$ ArcGIS/rest/services/MIP/Plan3/MapServer"

visible=" \{overlayToggle5. selected $\}$ "

alpha $="\{$ zoningAlphaslider.value $\} "$

/ >

<esri:ArcGISDynamicMapServiceLayer id="charpy5"

url="http: / / 664b-

$06 /$ ArcGIS/rest/services/MIP/Plan5/MapServer"

visible=" \{overlayToggle6. selected $\}$ " 


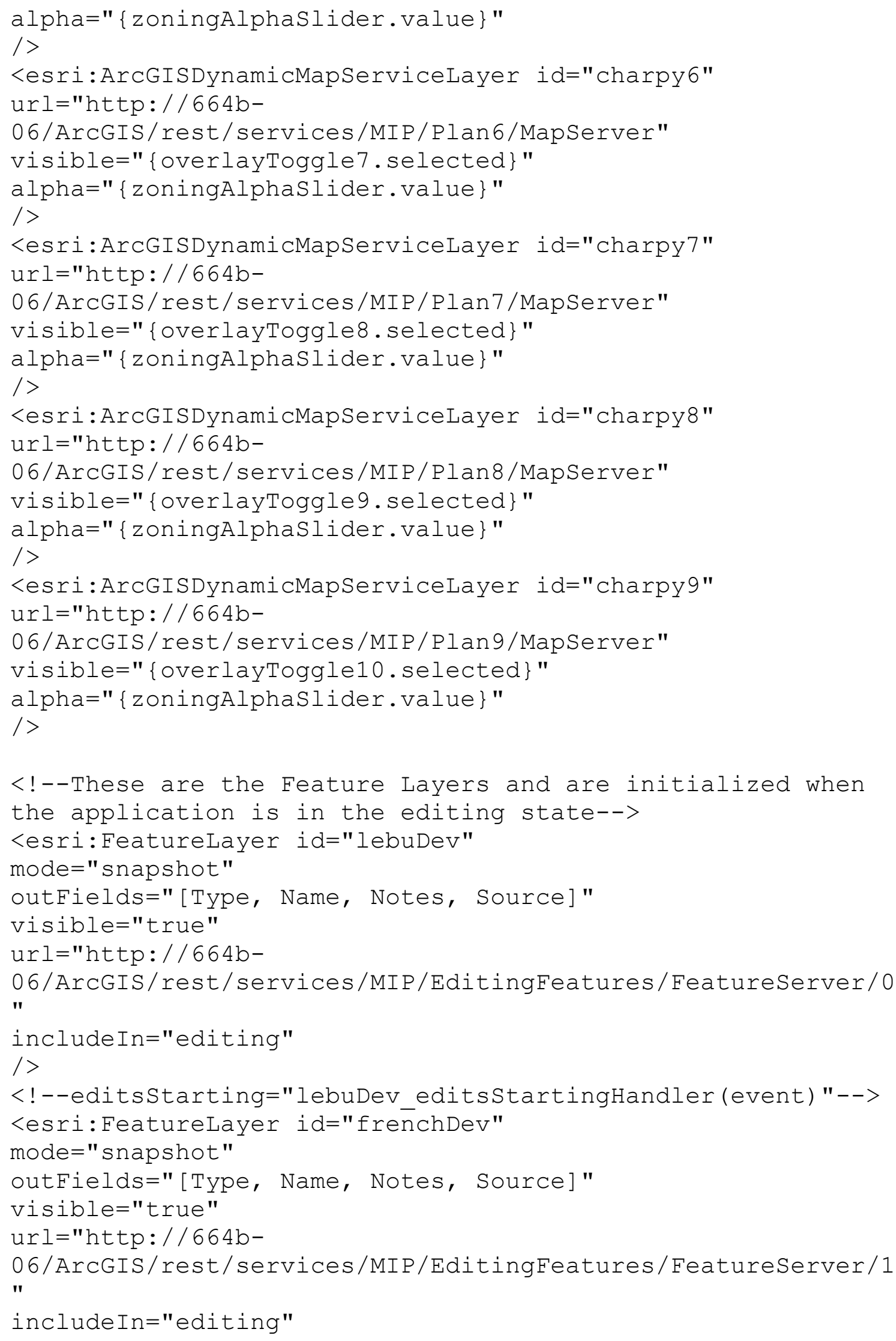




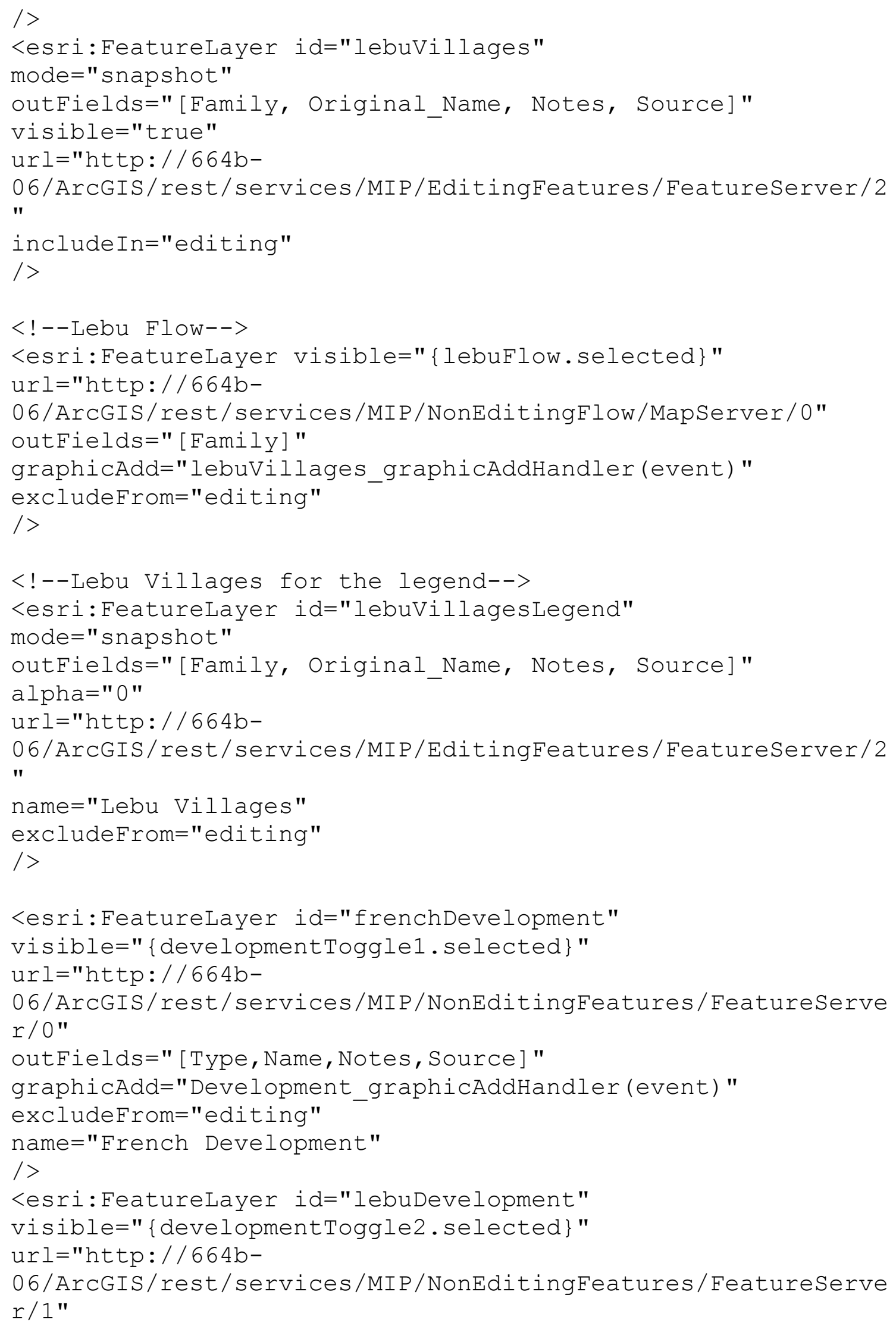


outFields=" [ Type, Name, Notes, Source] "

graphicAdd="Development_graphicAddHandler(event) "

excludeFrom="editing"

name="Lebu Development"

l>

<esri:FeatureLayer visible=" \{villageToggleSek.selected $\}$ " url="http://664b-

$06 /$ ArcGIS/rest/services/MIP/NonEditingFeatures/FeatureServe $r / 2 "$

outFields="[Family, Original_Name, Notes, Source]" graphicAdd="lebuVillages_graphicAddHandler(event)" excludeFrom="editing"

l>

<esri:FeatureLayer visible=" \{villageToggleSamb.selected " url $=$ "http: / / 664b-

$06 /$ ArcGIS/rest/services/MIP/NonEditingFeatures/FeatureServe $r / 3 "$

outFields="[Family, Original Name, Notes, Source]" graphicAdd="lebuVillages_graphicAddHandler(event)" excludeFrom="editing"

$1>$

<esri:FeatureLayer visible=" \{villageTogglePaye.selected $\}$ " url="http: / / 664b-

$06 /$ ArcGIS/rest/services/MIP/NonEditingFeatures/FeatureServe $r / 4 "$

outFields="[Family, Original_Name, Notes, Source]"

graphicAdd="lebuVillages_graphicAddHandler(event)"

excludeFrom="editing"

$1>$

<esri:FeatureLayer visible=" \{villageToggleNjaay.selected " url="http://664b-

$06 /$ ArcGIS/rest/services/MIP/NonEditingFeatures/FeatureServe $r / 5 "$

outFields="[Family, Original Name, Notes, Source]" graphicAdd="lebuVillages_graphicAddHandler(event) " excludeFrom="editing"

$1>$

<esri:FeatureLayer visible=" \{villageToggleNdoye.selected $\}$ " url="http: / / 664b-

$06 /$ ArcGIS/rest/services/MIP/NonEditingFeatures/FeatureServe $r / 6 "$

outFields="[Family, Original_Name, Notes, Source]" graphicAdd="lebuVillages_grap̄icAddHandler(event) " excludeFrom="editing"

/> 
<esri:FeatureLayer visible=" \{villageToggleMbenge.selected $\}$ " url="http: / / $664 \mathrm{~b}-$

$06 /$ ArcGIS/rest/services/MIP/NonEditingFeatures/FeatureServe $r / 7 "$

outFields="[Family, Original_Name, Notes, Source]"

graphicAdd="lebuVillages_graphicAddHandler(event) "

excludeFrom="editing"

$1>$

<esri:FeatureLayer visible=" villageToggleMBaye.selected " url="http: / / 664b-

$06 /$ ArcGIS/rest/services/MIP/NonEditingFeatures/FeatureServe $r / 8 "$

outFields="[Family, Original_Name, Notes, Source]"

graphicAdd="lebuVillages_graphicAddHandler(event) "

excludeFrom="editing"

$1>$

<esri:FeatureLayer visible=" villageToggleGueye.selected $\}$ " url="http: / / 664b-

$06 /$ ArcGIS/rest/services/MIP/NonEditingFeatures/FeatureServe $r / 9 "$

outFields="[Family, Original Name, Notes, Source]"

graphicAdd="lebuVillages_graphicAddHandler(event) "

excludeFrom="editing"

$1>$

<esri:FeatureLayer

visible=" $\{$ villageToggleGeneralLebu.selected $\}$ "

url="http: / / $664 \mathrm{~b}-$

$06 /$ ArcGIS/rest/services/MIP/NonEditingFeatures/FeatureServe $r / 10 "$

outFields="[Family, Original_Name, Notes, Source]" graphicAdd="lebuVillages_graphicAddHandler(event)" excludeFrom="editing"

$1>$

<esri:FeatureLayer visible=" \{villageToggleDiop.selected $\}$ " url="http: / / 664b-

$06 /$ ArcGIS/rest/services/MIP/NonEditingFeatures/FeatureServe $r / 11 "$

outFields="[Family, Original Name, Notes, Source]"

graphicAdd="lebuVillages_graphicAddHandler(event) "

excludeFrom="editing"

$1>$

<esri:FeatureLayer visible=" $\{$ villageToggleDione.selected $\}$ " url="http://664b-

$06 /$ ArcGIS/rest/services/MIP/NonEditingFeatures/FeatureServe r/12"

outFields="[Family, Original_Name, Notes, Source]" graphicAdd="lebuVillages_graphicAddHandler(event)" 


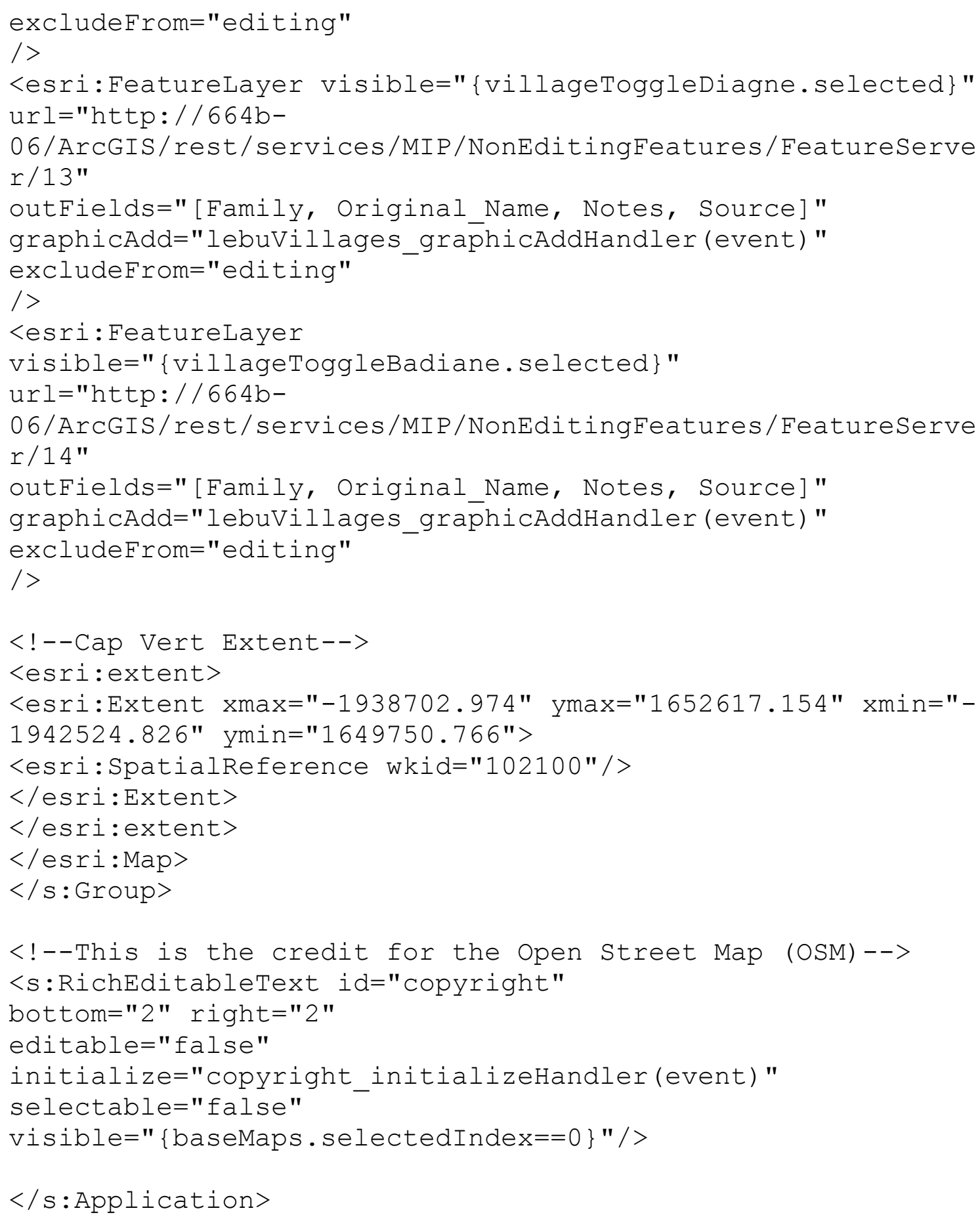




\section{Appendix B. Data Review Directions}

- Open the DataReview.mxd map document.

- Activate the Versioning toolbar in ArcMap.

(Customize > Toolbars $>$ Versioning)

- Click the List Layers By Source button in the Table of Contents.

- Click the SDE.WEBEDITING geodatabase (Figure B-1).

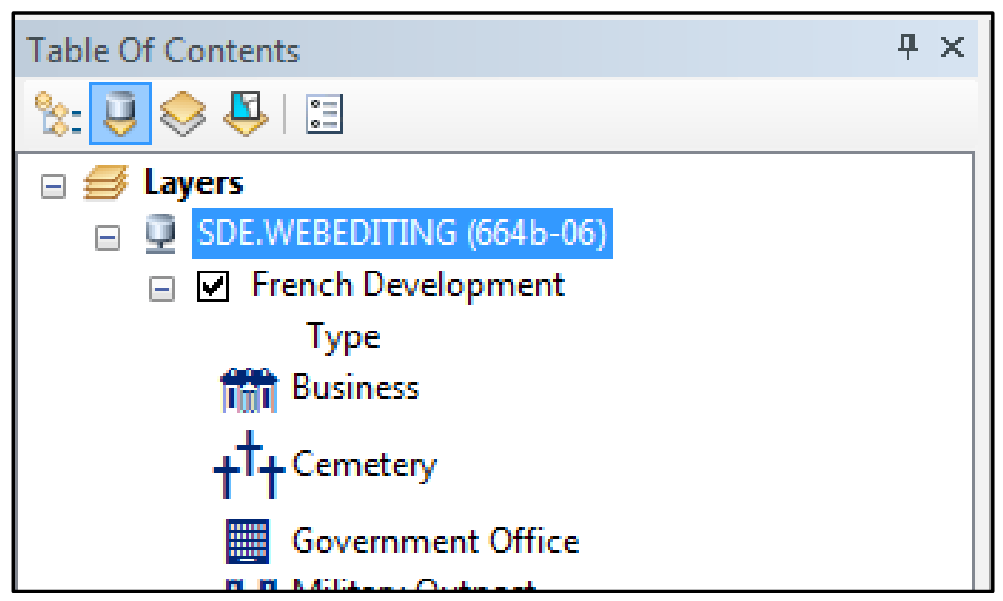

Figure B-1 Table of Contents

- Activate the Editing toolbar in ArcMap.

(Customize $>$ Toolbars $>$ Editing)

- Start an Edit Session (Figure B-2).

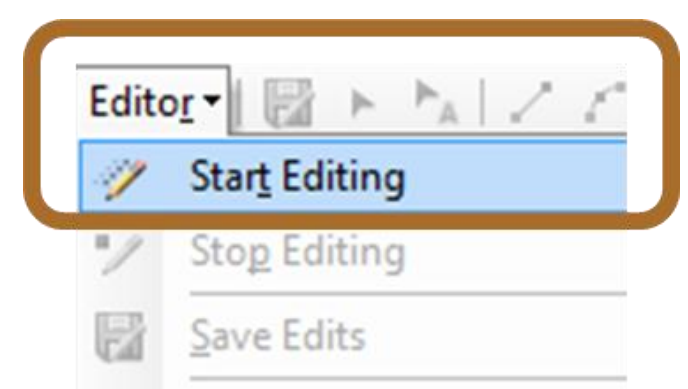

Figure B-2 Start an Edit Session

- Click the Version Changes button on the Versioning toolbar. In the Select A Version to Compare pop-up window, choose the DEFAULT database (Figure B$3)$. 


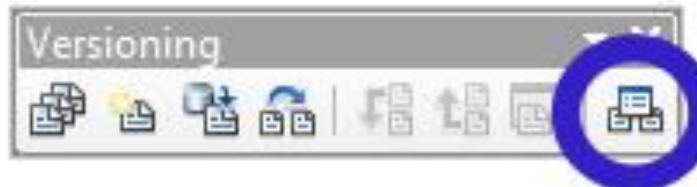

Figure B-3 Version Changes Button

- Expand the changes tree for each feature class. Inspect the changes by clicking on the feature (Figure B-4).

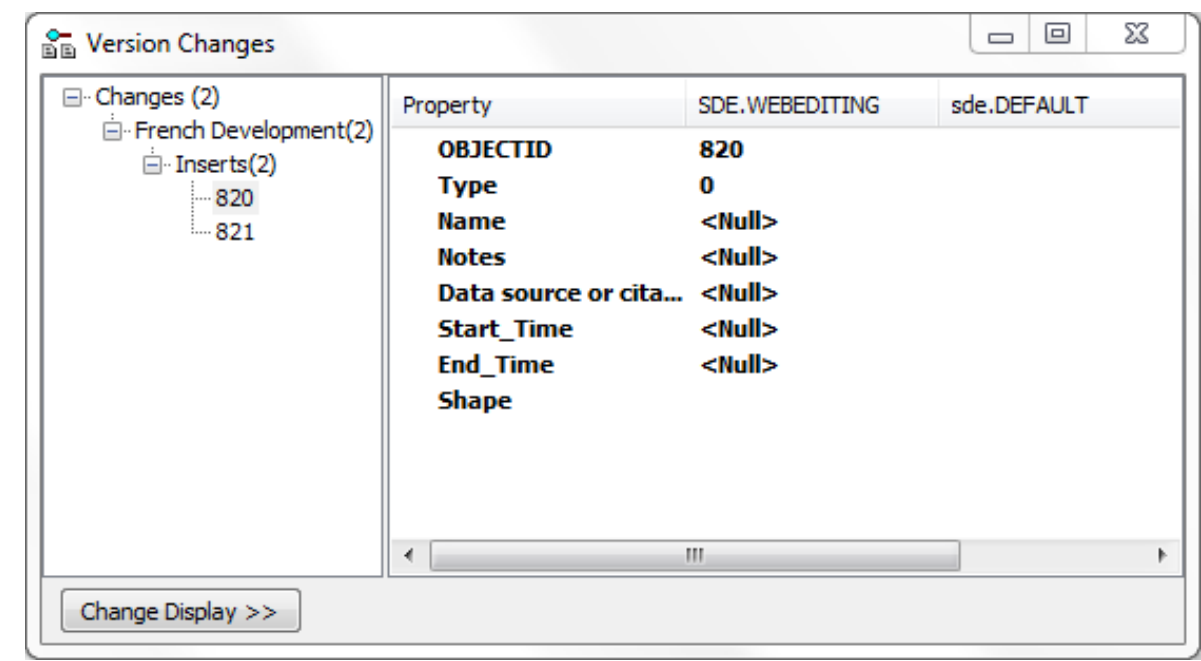

Figure B-4 Version Changes Window

- Click each change to view the attributes. To see the feature on the map, rightclick the edit in the Version Changes window and use the pan, zoom, or select tools (Figure B-5).

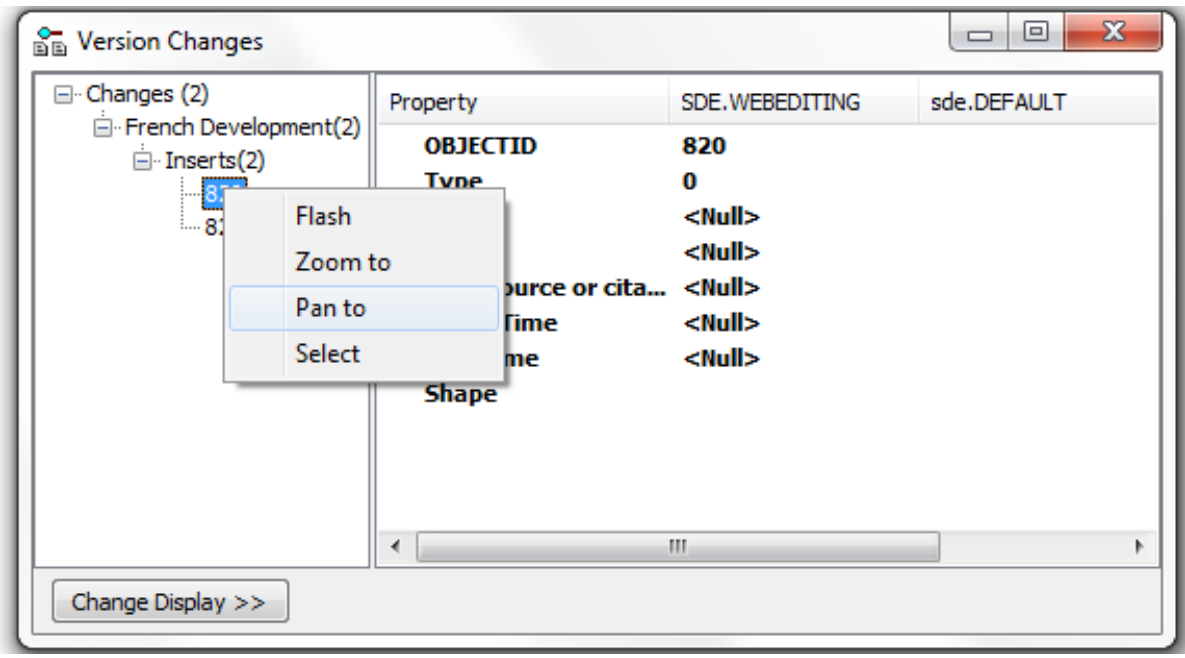

Figure B-5 Inspect the Changes

- If an insertion edit is invalid, select it, and then press Delete. 
- If an update edit is invalid, select the feature, and correct the incorrect attributes in the attribute table to be correct. This can quickly be done using the Attributes button on the editor toolbar (Figure B6).

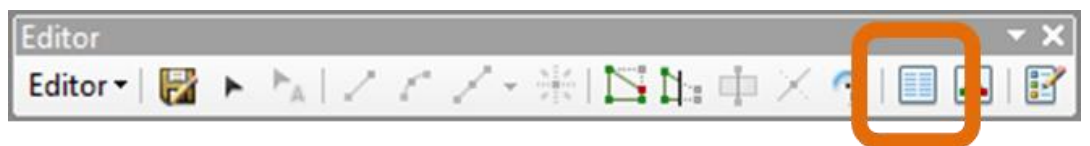

Figure B-6 Attribute Button on the Editor Toolbar

- When the data review is complete, click the Reconcile button on the Versioning toolbar. Accept the default values and click OK (Figure B-7).

*Note: To undo a reconcile, simply end the edit session without saving (Editing >Stop Editing).

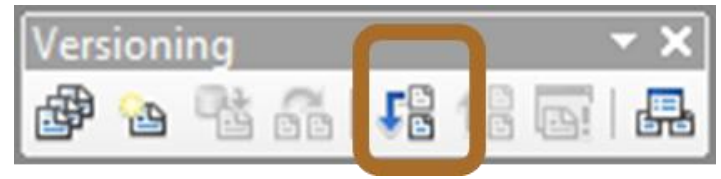

Figure B-7 Version Changes Button

- Click the Post button on the Versioning toolbar (Figure B-8).

*Note: A Post cannot be undone, so be certain you are ready

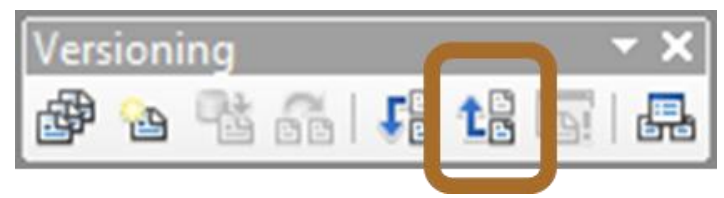

Figure B-8 Version Changes Button

- Now the data review is complete, and the edits have been applied. 